\title{
3D Convective/Stratiform Echo Type Classification and Convectivity Retrieval from Radar Reflectivity
}

\author{
Michael Dixon ${ }^{\mathrm{a}}$ and Ulrike Romatschke ${ }^{\mathrm{a}}$

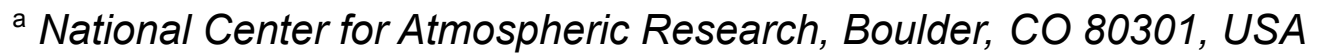 \\ Corresponding author: Michael Dixon, dixon@ucar.edu
}

This work has not yet been peer-reviewed and is provided by the contributing authors as a means to ensure timely dissemination of scholarly and technical work on a noncommercial basis. Copyright and all rights therein are maintained by the authors. It is understood that all persons copying this information will adhere to the terms and constraints invoked by each author's copyright. This work may not be reposted without explicit permission of the copyright owner. 


\title{
3D Convective/Stratiform Echo Type Classification and Convectivity Retrieval from Radar Reflectivity
}

\author{
Michael Dixon ${ }^{\mathrm{a}}$ and Ulrike Romatschke ${ }^{\mathrm{a}}$

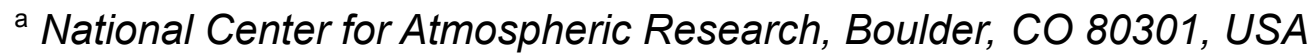 \\ Corresponding author: Michael Dixon, dixon@ucar.edu
}

\begin{abstract}
The newly developed ECCO (Echo Classification from COnvectivity) algorithm identifies convective and stratiform types of radar echo in three dimensions. It is based on the calculation of reflectivity texture a measure of the heterogeneity of the radar echoes on each horizontal plane in a 3D Cartesian volume. Reflectivity texture is translated into convectivity, which is a newly invented quantitative measure of the convective nature of each three dimensional radar grid point. It ranges from 0 (100\% stratiform) to 1 (100\% convective). By thresholding convectivity, a more traditional qualitative categorization is obtained which classifies radar echoes as convective, mixed, or stratiform. In contrast to previous algorithms, these echo type classifications are provided on the full three dimensional grid of the observed reflectivity field. The vertically resolved classifications, in combination with temperature data, allow for sub-classifications into shallow, mid, deep, and elevated convective features, and low, mid, and high stratiform regions - again in three dimensions.

The algorithm was validated using datasets collected during the PECAN field campaign, which took place over the US Great Plains in 2015. An analysis of lightning counts shows that the majority of lightning flashes occur in regions classified as deep convective features by ECCO. A statistical comparison of ECCO echo types with the well established GPM radar precipitation type categories show strong agreement. ECCO was also applied to radar grids for the Continental US, the United Arab Emirates, Australia, and Europe, illustrating its robustness and adaptability.
\end{abstract}




\section{Introduction}

\subsection{Background and existing methods}

The terms convective and stratiform are applied to both clouds and precipitation. Included in the early cloud classification scheme by Howard (1803), stratus, which is derived from the latin verb sternere (spread), is recognised as one of three main cloud types. The American Meteorological Society (2021a) defines stratiform as "Descriptive of clouds of extensive horizontal development, as contrasted to the vertically developed cumuliform types" which again points to the horizontal nature of these clouds. On the other hand, convective cloud is defined as "A cloud that owes its vertical development, and possibly its origin, to convection." (American Meteorological Society 2021b), which is in alignment with the cumulus type clouds defined by Howard (1803), and emphasizes the vertical nature of such clouds. When transferring the concept of convective and stratiform to precipitation, the precipitating cloud genera are relevant. Houze (2014) specifically mentions stratiform precipitation falling from nimbostratus clouds and convective precipitation falling from active cumulus and cumulonimbus clouds. He notes that "These cloud types may occur separately or entangled with each other in the same cloud complex" which indicates that stratiform precipitation can be observed in regions of convection, and it is therefore important to distinguish between the noun convection and the adjective convective (Houze 1997). In meteorology, the noun convection generally encompasses clouds and precipitation which have their origin in convective processes but can contain stratiform clouds and precipitation as the convection matures. In contrast, the adjective convective describes clouds and precipitation associated with young and active convection (Houze 1997).

Even though different physical and microphysical processes are observed in convective vs. stratiform clouds and precipitation, the terms stratiform and convective on a fundamental level refer to the horizontal vs. vertical structure of clouds, respectively. Separating radar observations into convective and stratiform components has a long history as radar can observe the horizontal and vertical structure of clouds and precipitation. It is therefore not surprising that classification algorithms are often based on these properties. Investigating the homogeneity of clouds and precipitation on the horizontal plane has proven especially useful as stratiform cloud and precipitation layers will exhibit a homogeneous structure while vertically oriented convective cells will present as heterogeneous insertions.

One of the first robust convective/stratiform partitioning algorithms for precipitation echoes, which relies on the horizontal structure of radar reflectivity, was developed by Steiner et al. (1995, SHY95 hereafter). This method has been influential and is widely used and cited up to the present. The concepts and ideas presented in that work have been incorporated in most of the subsequently-developed methods. SHY95 provided a thorough explanation of the processes that dominate stratiform regions, and how stratiform areas appear when observed by radar: (i) the vertical velocity of the air tends to be much smaller than the terminal velocity of the hydrometeors, so that radar-observed vertical velocity is dominated by the particle fall speed; (ii) the melting layer presents as the well-known bright-band feature, a narrow horizontal layer of high reflectivities which has planar characteristics; and (iii) the horizontal structure of the reflectivity field is smoother in stratiform regions than in convective ones. Since vertical velocity is not well resolved by most scanning radars, process (i) is generally not utilized for convective/stratiform partitioning. The presence or absence of the bright-band (process ii) is a feature of some of the methods. SHY95 relies on both the intensity of the horizontal structure of reflectivity at a single selected altitude ( $3 \mathrm{~km})$ - defining a 'peakedness' metric to help identify regions with more or less variability. As with most of the methods in the literature, SHY95 operates on a Cartesian grid, and specifies that any grid cell with a reflectivity above 40 
$\mathrm{dBZ}$ must be convective. It also provides a heuristic rule for extending the influence of convective centers to surrounding grid points.

The method of Biggerstaff and Listemaa (2000) extended SHY95 by incorporating the vertical and horizontal gradient of reflectivity and a bright-band fraction. They showed improvement over SHY95 in correctly identifying heavy stratiform rain and better identifying the periphery of convective cores as convective.

The method of Anagnostou (2004) uses a machine-learning neural network approach, with six input features that are computed from the radar observations. The features include information on the vertical structure as well as the reflectivity intensity at the target point, and the standard deviation of the reflectivity within an $11 \mathrm{~km}$ radius of the target grid point. The training data set (truth) is provided by the convective/stratiform classification from the Precipitation Radar onboard the Tropical Rainfall Measuring Mission (TRMM PR, Awaka et al., 1997). Unfortunately the paper does not report the details of the neural network (weights, transfer function details) so it may be difficult to repeat the work and confirm the results. The computed statistics show a probability of detection of 0.97 for stratiform and between 0.5 and 0.6 for convective regions, indicating that it worked considerably better in identifying stratiform areas than convective ones.

The method proposed by Yang et al. (2013) takes a similar approach to Anagnostou (2004), except that it replaces the neural network with fuzzy logic, and uses only four features: (i) reflectivity at the target point, (ii) Vertically Integrated Liquid (VIL), (iii) the standard deviation of the reflectivity within an $11 \mathrm{~km}$ radius of the target grid point, and (iv) the product of radar top height and the reflectivity at $2 \mathrm{~km}$. Case study results are shown, but no truth data set was used, so verification statistics are not available.

The method of Powell et al. (2016) is based on SHY95, but uses the radar data in its native polar coordinates instead of transposing them into Cartesian coordinates. They add several sub-classifications to the categories originally proposed by SHY95. Verification was performed using simulated storms from a cloud-resolving version of the Weather Research and Forecasting (WRF) model. Using polar coordinates allowed the algorithm to better identify shallow convection close to the radar site.

Finally, the method of Wang et al. (2021) uses a machine-learning Support Vector Machine (SVM) technique applied to polarimetric radar data. SVMs apply supervised learning to classification problems. The input variables used were reflectivity (DBZ), differential reflectivity (ZDR), and the so-called 'Separation Index' which discriminates convective from stratiform rainfall based on the estimated drop-size distribution (DSD). The DSD is estimated from DBZ and ZDR using previously-derived regression equations. Since this is a supervised learning technique, training data was provided by the Multi-Radar-Multi-Sensor (MRMS) precipitation classification algorithm (Zhang et al. 2005).

This list of convective/stratiform partitioning algorithms is not exhaustive. Other examples include an algorithm developed to be used in the rainfall retrieval algorithm for cloud radar data from CloudSat (Haynes et al. 2009; Haynes 2018), the algorithm by Awaka et al. (1997, 2007, 2016), applied to TRMM PR data and data from the Global Precipitation Measurement Dual-frequency Precipitation Radar (GPM DPR), and those developed by Penide et al. (2013) or Roberto et al. (2016). 


\subsection{Objectives}

A full explanation of why we need to separate convective from stratiform radar echo is beyond the scope of this paper, and has been extensively discussed elsewhere, e.g. in the publications mentioned above. The short explanation is that different physical and microphysical processes dominate in convective and stratiform regions, and the heating profile of the atmosphere differs substantially in areas with different types of processes (Houze 1997). The type of echo is important for Quantitative Precipitation Estimates (QPE) because different radar-based relationships apply in convective and stratiform areas (Steiner and Houze 1997; Thompson et al. 2015), and for improving the accuracy of numerical models (Lang et al. 2003).

With many convective/stratiform partitioning algorithms already in existence, why do we need another one? One challenge with existing methods is their relative complexity - more parameters means that more variables need to be tuned. They were often developed with a single application in mind, for specific climatic conditions, and to answer specific research questions. Most existing algorithms generate a 2 dimensional (2D) product, with a single class for each horizontal $(x, y)$ grid point. Furthermore, they provide qualitative classes of convective and stratiform (and sometimes sub-categories) rather than providing a quantitative measure of how convective or stratiform a specific grid point is likely to be.

This paper presents the Echo Classification from COnvectivity (ECCO) algorithm which partitions Cartesian radar reflectivity into convective, stratiform, and mixed regions. ECCO provides the following:

- Simplicity to the extent possible.

- A 3D classification scheme that differentiates cloud and precipitation echo type not only in the horizontal but also in the vertical dimension.

- Convectivity - a 3D unitless quantity ranging from 0 to 1 , designed to describe the likelihood that a grid cell has convective as opposed to stratiform characteristics. It is a numeric measure for how convective or stratiform a specific cloud/precipitation element is.

- The traditional convective/stratiform classification (with sub-categories) in two and three dimensions.

- Adaptability to different regions (tropical vs. mid-latitude), seasons, and data sets (ground-based, airborne and space-borne radars with different wavelengths) without the need for extensive tuning, while still providing the flexibility to adjust for specific user needs.

- A community application (Ecco) that is available in the open-source Lidar Radar Open Software Environment (LROSE, Dixon and Javornik, 2016).

Section 2 lists the data sets used for the development and validation of ECCO. Section 3 describes the algorithm itself. Section 4 shows, through validation, that ECCO produces skillful results. Section 5 shows examples of applying ECCO to data from various locations around the world. Section 6 lists the conclusions. Appendix A describes the clumping method for grouping convective regions into contiguous objects. Appendix B lists the ECCO algorithm parameters and their default values. Appendix $\mathrm{C}$ details the logic used in the advanced 3D product. Appendix D lists the integer values assigned to each echo type category by the Ecco application. 


\section{Data}

Instructions on how to obtain the datasets described below can be found in the Data Availability Statement at the end of this paper.

\subsection{Radar data}

The ECCO algorithm was initially developed using radar data gathered for the Plains Elevated Convection at Night (PECAN) field campaign (Geerts et al. 2017) that took place over the US Great Plains (Kansas) from June 1 to July 16, 2015. PECAN was designed to advance the understanding of continental, nocturnal, warm-season precipitation. The NEXRAD 3D Multi-Radar Multi-Sensor (MRMS) product (Zhang et al. 2005) was sub-sectioned to include the PECAN domain in Kansas, plus some areas from surrounding states. The MRMS Cartesian grid uses a latitude/longitude projection, with a $0.01^{\circ}$ (roughly $1 \mathrm{~km}$ ) grid spacing in the horizontal dimensions. The area used in this study spanned from 110 to $90^{\circ} \mathrm{W}$ and from 30 to $45^{\circ} \mathrm{N}$. The vertical axis has 33 levels from 0.5 to $19 \mathrm{~km}$ in altitude, with $0.25 \mathrm{~km}$ vertical spacing up to 3 $\mathrm{km}, 0.5 \mathrm{~km}$ vertical spacing from 3 to $9 \mathrm{~km}$, and $1.0 \mathrm{~km}$ spacing from 9 to $19 \mathrm{~km}$.

We tested the MRMS ECCO results against data from the space-borne GPM DPR, which comprises Ku-band and Ka-band instruments. The reflectivity and precipitation type fields from the Version 6 GPM DPR Ku Precipitation Profile 2A product (Iguchi and Meneghini 2016) used in this study were collected during PECAN over the MRMS area described above. The DPR data is provided on a $5 \times 5 \mathrm{~km}$ horizontal grid and on 176 levels (radar gates) at $0.125 \mathrm{~km}$ spacing in the vertical axis. To facilitate a comparison with results from the MRMS PECAN radar grid we interpolated the GPM DPR data onto a latitude-longitude grid of $0.025^{\circ}(\sim 2.5 \mathrm{~km})$ resolution, with the same vertical levels as the MRMS grid. The reflectivity was linearly interpolated, while the precipitation type (which classifies each vertical column as either convective, stratiform, or other) was interpolated using the nearest neighbor technique.

To assess the adaptability of the algorithm to different regions and radars it was applied to several other radar datasets, namely:

- The NEXRAD 3D MRMS data over the full CONtinental USA (CONUS) for several months during 2021. This product has the same resolution as the PECAN MRMS grid (see first paragraph in this section).

- A 3D radar mosaic from the Sydney region of southeast Australia, obtained via personal communication with personnel at the Australian Bureau of Meteorology (BOM) in Melbourne. The horizontal and vertical resolution is $0.75 \mathrm{~km}$.

- A 3D radar mosaic from the United Arab Emirates (UAE), obtained via personal communication with personnel at the UAE National Center of Meteorology (NCM). The horizontal and vertical resolution is 0.5 $\mathrm{km}$.

- Data from the Operational Program on the Exchange of Weather Radar Information (OPERA). OPERA produces Pan-European radar composites (Huuskonen et al. 2014; Saltikoff et al. 2019). OPERA does not provide three-dimensional data so we use two-dimensional fields of column-maximum reflectivity to assess the capability of the algorithm to process two-dimensional data. This dataset is provided at a 2 $\mathrm{km}$ grid resolution on a Lambert conformal projection. 


\subsection{Temperature data}

If distinction between different echo sub-classifications is desired (e.g., shallow, mid-level, and deep convection, Section 3.4), ECCO in its $3 \mathrm{D}$ form, requires a temperature profile. We used the following temperature data:

- For the MRMS and GPM cases, we used model output data from the NOAA Rapid Update Cycle (RUC) model.

- For the Sydney and UAE cases, we used publicly-available sounding data from the on-line archive at the University of Wyoming.

- Since OPERA is a 2D product, sub-classification is not possible and the temperature profile is not required.

\subsection{Lightning data}

For the purpose of verifying the performance of the algorithm in the PECAN case, we used cloud-to-ground lighting data from the National Lightning Detection Network (NLDN, Orville et al., 2002).

\section{ECCO algorithm description}

\subsection{The texture of reflectivity in the horizontal dimensions}

As mentioned above (Sec. 1.1), the horizontal heterogeneity of clouds and precipitation directly relates to the convective or stratiform nature of a feature. ECCO calculates this heterogeneity using reflectivity data that has been remapped onto a regular Cartesian grid. The following operations are therefore performed on each horizontal plane in the grid.

We define a horizontal circular area (kernel) with a specified radius, over which the subsequent calculations are performed. The default radius is set to $7 \mathrm{~km}$ (see Appendix B for all algorithm parameters and their default values). For each plane in the 3D grid, we iterate through each grid point containing non-missing reflectivity, centering the kernel on each of those target points. We calculate the fraction of points within the circle that have non-missing reflectivity. If the fraction of non-missing points meets or exceeds 0.25 , we designate the center point 'active'. Subsequent calculations are performed just for the active target points. If, as is usual, there is valid reflectivity at more grid points lower down than higher up, then the computations will be applied at more points for the lower levels than for higher levels.

For each active target point we assess the heterogeneity of the reflectivity within the surrounding circle. The smoother the reflectivity the more likely that the area is stratiform. Heterogeneity can have two components: (a) variability of the reflectivity in the echo itself, and (b) reflectivity gradient at the edge of a feature. We need to remove (b) before we compute (a).

To exclude reflectivity gradients, using $2 \mathrm{D}$ linear regression we fit an $(\mathrm{x}, \mathrm{y})$ plane to the non-missing reflectivity points within the kernel. The plane will be tilted if there is a gradient. Note that we only perform the fit if at least 0.67 of the area within the circle has non-missing reflectivity. If it is less than this, the texture is computed from the original reflectivity. The 0.67 check is more stringent than the previously-mentioned 0.25 fraction check because fitting the slope and correcting for it is more demanding of data quality than computing the texture.

The 2D linear reflectivity fit $D B Z_{f i t}$ is: 


$$
D B Z_{f i t}=a x+b y+c
$$

where $a$ is the slope in the $x$ direction, and $b$ is the slope in the $y$ direction, while $c$ is the mean value. We remove the effect of the $a$ and $b$ slopes from the reflectivity data by subtracting the fit value and adding the mean reflectivity $D B Z_{\text {mean }}$ for each point in the kernel:

$$
D B Z_{\text {corr }}=D B Z_{x, y}-D B Z_{f i t}+D B Z_{\text {mean }}
$$

Adding the mean retains the information on the echo strength. We then compute adjusted reflectivity $D B Z_{a d j}$ by subtracting a base reflectivity $D B Z_{\text {base }}$ :

$$
D B Z_{\text {adj }}=D B Z_{\text {corr }}-D B Z_{\text {base }} \cdot
$$

$D B Z_{\text {base }}$ is the lower bound of reflectivity that is deemed relevant to identifying convective echo, i.e., below this level the information from measured reflectivity is not useful for this purpose. For S-, C- and X-band radars, convective echo is generally associated with reflectivity values above $25 \mathrm{dBZ}$, so we can safely set $D B Z_{\text {base }}$ to 0 . However, for Ka-band and $\mathrm{W}$-band radars, for which precipitation occurs more in the Mie-scattering region (Ellis and Vivekanandan 2011; Zhang 2019), cloud echo is often observed at much lower and even negative reflectivity values. For these wavelengths, setting $D B Z_{\text {base }}$ at a low negative value assures that all relevant information is used in the calculations. For Ka- and W-band radars a $D B Z$ base value of $-10 \mathrm{dBZ}$ has been used (Romatschke and Dixon 2022) and especially for the W-band radar this could likely be set even lower.

We now calculate the horizontal heterogeneity of the corrected reflectivies, which we call the reflectivity texture $T D B Z$, as:

$$
T D B Z=\sqrt{\operatorname{stdev}\left(D B Z_{a d j}^{2}\right)}
$$

$T D B Z$ is calculated for each active point in the radar grid, hence the result is a $3 \mathrm{D}$ field. This computation is performed in logarithmic space and the units are $\mathrm{dBZ}$. If $D B Z_{a d j}$ is less than a lower bound of 1.0 , it is set to 1.0 , because given the square of $D B Z_{a d j}$ in the formula for $T D B Z$ we do not want to square a negative value, thereby giving weight to low values. This is the primary reason for introducing $D B Z_{b a s e}$. An example of the reflectivity texture is shown in Fig. 1c,d (left values on the colorbar).

Before settling on this definition of $T D B Z$, a number of ideas were tested for describing the horizontal smoothness of reflectivity. The concept of using the square of the reflectivity came from experience with reflectivity texture in the identification of ground clutter. The Radar Echo Classifier (REC, Kessinger et al., 2003) and the Clutter Mitigation Decision algorithm (CMD, Hubbert et al. 2009) both define reflectivity texture in a similar manner, and it was found to perform better than other metrics (such as the standard deviation of reflectivity). The advantage of squaring the reflectivity is that it makes the texture sensitive to both the absolute value of reflectivity and to the spatial variability. This is helpful because in convective, as compared to stratiform regions, both the reflectivity and the spatial variability of reflectivity tend to be 
higher. The reflectivity texture is therefore a measure of both the heterogeneity of the reflectivity field in the horizontal, and the intensity of the reflectivity.
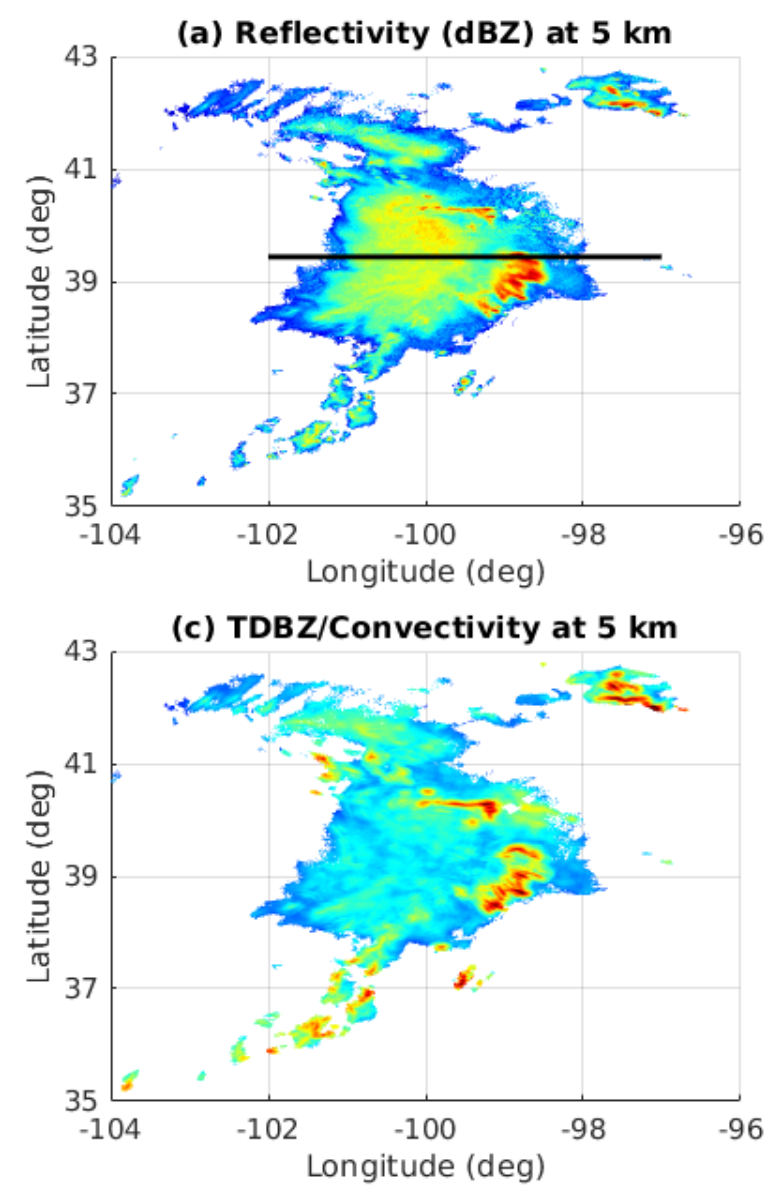

(e) Basic echo type

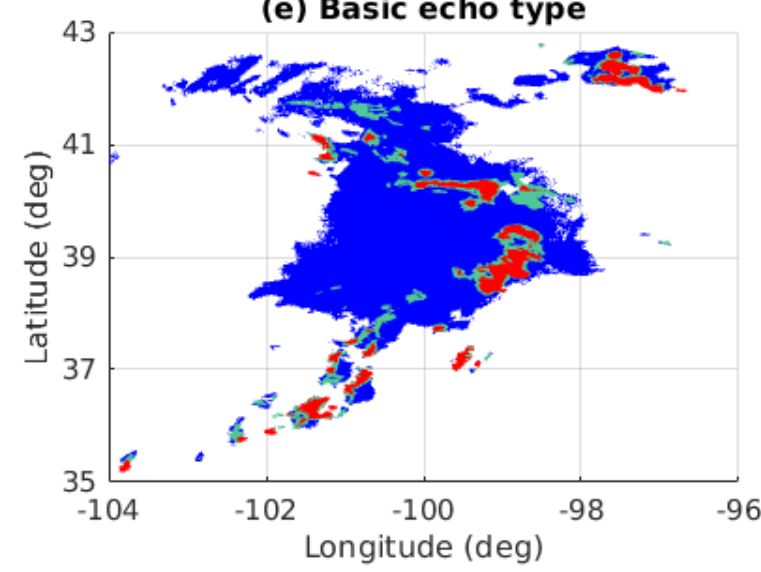

(b) Reflectivity

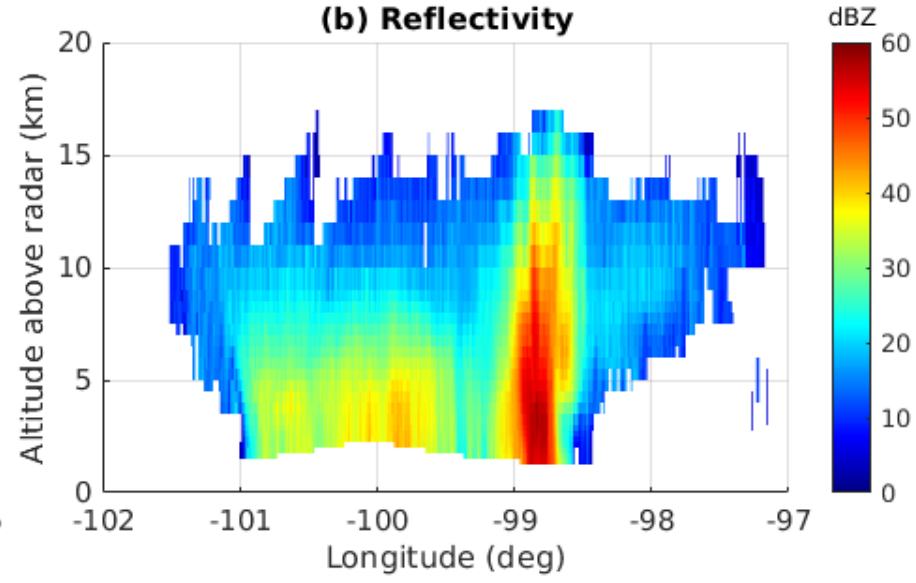

(d) TDBZ/Convectivity

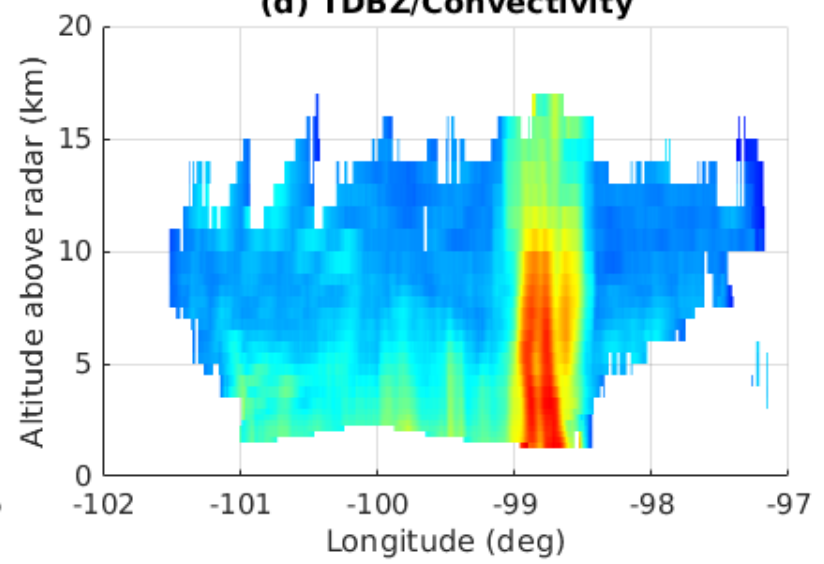

(f) Basic echo type

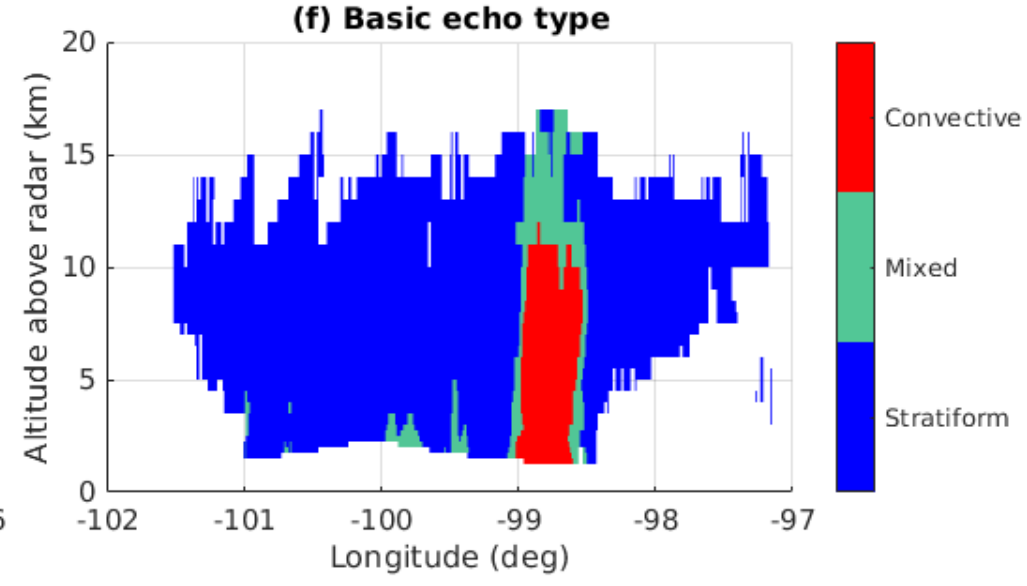

Fig. 1: Mesoscale Convective System (MCS) observed during PECAN, 2015-07-15 08:04 UTC. Horizontal cross sections at $5 \mathrm{~km}$ altitude (left panels) and vertical cross sections along black line in (a, right panels) of reflectivity $(a, b)$, reflectivity texture and convectivity $(c, d)$, and basic echo type $(e, f)$.

\subsection{Convectivity}

We now introduce the concept of convectivity, a unitless field that indicates the likelihood that a region is convective in nature as opposed to stratiform. We use a transfer function (Fig. 2) to map TDBZ onto convectivity such that convectivity takes values from 0.0 to 1.0 by mapping $T D B Z$ values of less than $0 \mathrm{dBZ}$ 
(algorithm default) to 0 and $T D B Z$ values of more than $30 \mathrm{dBZ}$ (default) to 1 , with a linear gradient in between. (These settings are configurable, depending on the radar type and grid resolution. See Section 3.6 and Appendix B.) The higher the convectivity value, the more likely it is that that point is convective.

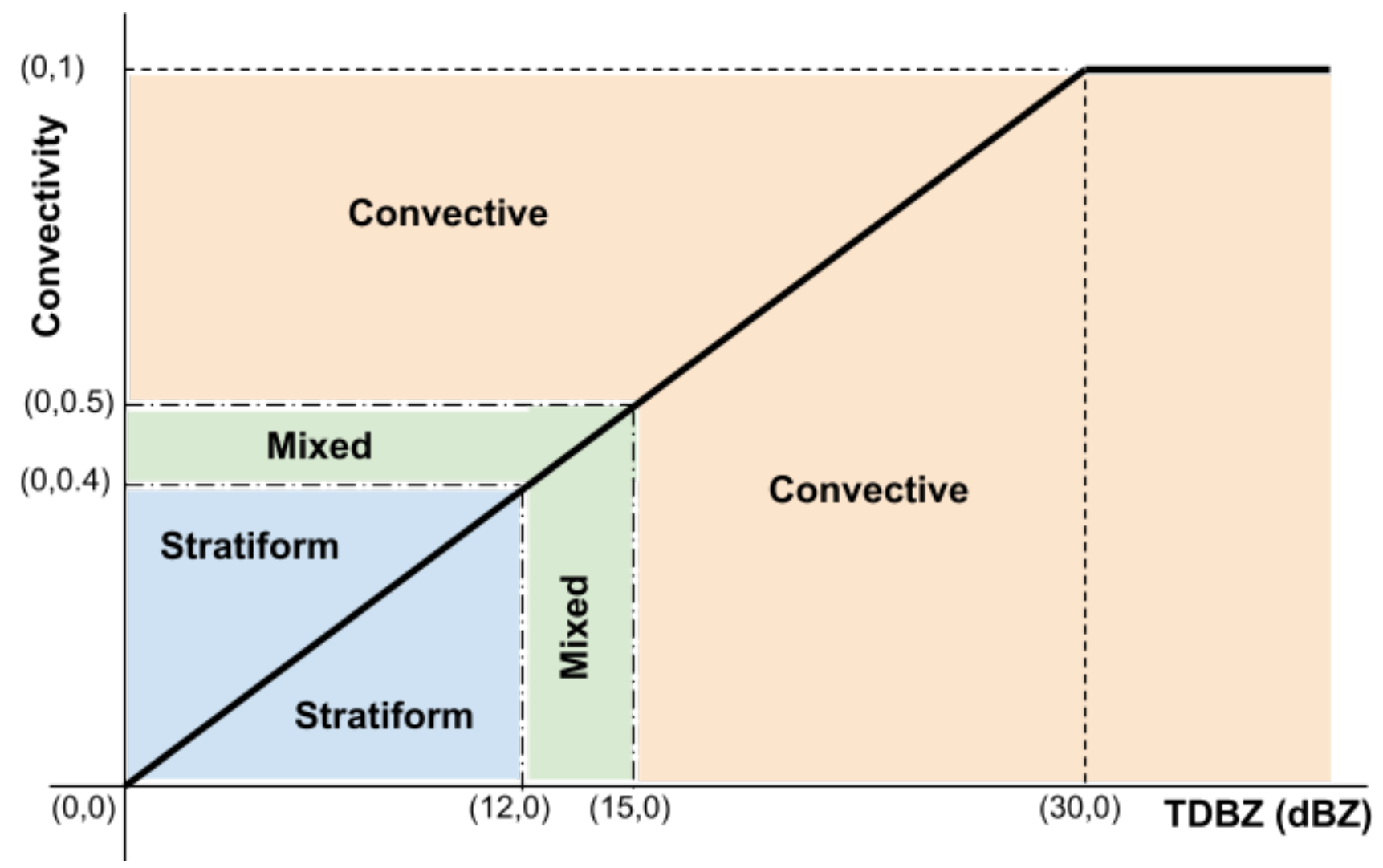

Fig. 2: Conversion of TDBZ into convectivity (for horizontal grid resolution of $1 \mathrm{~km}$ ). texture_limit_low = $0 \mathrm{dBZ}$, texture_limit_high $=30 \mathrm{dBZ}$ (see Appendix B).

Like TDBZ, convectivity is a 3D field. An example is shown in Fig. 1c,d with an alternative interpretation of the color scale (right values on the colorbar). High convectivity values are observed in the deep convective core of the Mesoscale Convective System (MCS) while the bright band region (-101 to $-99.4^{\circ} \mathrm{W}, 5 \mathrm{~km}$ altitude and below, Fig. 1a), which indicates stratiform precipitation, has low convectivity, as desired, even though the reflectivity values themselves are high (Fig. 1a,b). The advantage of using convectivity, as opposed to $T D B Z$ directly, is that results from different geographic regions or algorithm settings will be quantitatively comparable.

\subsection{Basic ECCO 3D echo type classification from convectivity}

The convectivity field gives us a quantitative measure of how likely each grid point is to be convective or stratiform in nature. It can be used directly in suitably-designed applications. For users who desire the more traditional qualitative classification of previous methods, convectivity can be simply converted into a basic convective/stratiform echo type partition by applying the appropriate thresholds. Figure 2 shows the default values used in the algorithm for such partitioning, assuming a $1 \mathrm{~km}$ horizontal grid resolution. Points with convectivity below 0.4 are set to stratiform, between 0.4 and 0.5 to mixed, and above 0.5 to convective. Note that in contrast to previous algorithms, the resulting partitioning field is 3-dimensional (Fig. $1 \mathrm{e}, \mathrm{f})$. We would also like to point out that up until this point, the only observed quantity required is radar reflectivity on a Cartesian grid. 


\subsection{Advanced ECCO 3D echo type classification using 3D objects}

The basic 3D convectivity and classification fields described above may meet the requirements of many applications. However, we can provide more detail by refining the classification into sub-categories. In the advanced classification, we divide the troposphere vertically into three regions:

- the lower region in the warm part of the troposphere below the freezing level, i.e., the $0{ }^{\circ} \mathrm{C}$ isotherm.

- the mid region, between the $0{ }^{\circ} \mathrm{C}$ isotherm and the divergence level (default: $-25^{\circ} \mathrm{C}$ isotherm).

- the upper region, above the divergence level.

Here we refer to the divergence level - the level above which divergence occurs in large storms and anvil forms. Kuang and Hartmann (2007) find the divergence level at $\sim-30^{\circ} \mathrm{C}$ while Igel et al. (2014) find the lower edge of anvil clouds at $\sim-15^{\circ} \mathrm{C}$. We prefer isotherms rather than altitudes to allow the method to adapt to different climatic regimes. In testing our algorithm, we found that a divergence level of $-25^{\circ} \mathrm{C}$ works well, but this can be adjusted based on the climatic regime. Integrating isotherms into the algorithm requires a temperature profile, either from soundings or a model. Note that using different types of temperature data, e.g. model vs. sounding, will change the sub-classification only. It will not affect the basic distinction between convective, mixed, and stratiform echo. In our PECAN test case we use the NOAA RUC model, while other cases rely on sounding profiles. Using the temperature field from the model, we compute, at each Cartesian $(x, y)$ grid point, the altitudes of the lower-mid and mid-upper separation boundaries. These separation boundaries are $2 \mathrm{D}$ fields. If a model is not available, constant altitudes (in $\mathrm{km}$ ) for the lower-mid and mid-upper separation boundaries can be specified instead, e.g., determined from a suitable sounding.

Convection is generally associated with some entity, such as a convective cell, a multicellular storm, or a supercell. These entities may be organized as part of a larger complex, such as a squall line or MCS. In the advanced version of the ECCO algorithm we refine our echo type categories to consider the vertical extent of the convective entities - for example, do we have shallow or deep convective features? To achieve this we analyze the identified convective regions as objects, using a method referred to as clumping (Dixon and Wiener 1993, see Appendix A for details).

Using the logic detailed in Appendix $\mathrm{C}$, we then categorize the echo type of each convective feature (clump) with convectivity greater than 0.5 as follows:

- Feature top extends significantly into the upper region: convDeep (deep convective feature).

- Feature top extends significantly into the mid but not the upper region: convMid (mid convective feature).

- Feature is mostly contained within the lower region: convShallow (shallow convective feature).

- Feature base is significantly elevated: convElev (elevated convective feature).

To categorize the remaining (i.e. non-convective) active grid points, with convectivity less than 0.5 , we apply the following logic:

- Convectivity is between 0.4 and 0.5: mixed.

- Grid point is in upper region: stratHigh (high stratiform echo).

- Grid point is in mid region: stratMid (mid level stratiform echo).

- Grid point is in lower region: stratLow (low stratiform echo). 
As in the basic classification, the advanced classification is a 3D field and examples are shown in Fig. 3. Shallow, mid, and deep convective cells are clearly identified by the algorithm (Fig. 3a-c). They are surrounded by some mixed echo while the remaining echo is classified as stratiform. Elevated convective echo, which is embedded within stratiform regions, is also clearly identified (Fig. 3d-f). Note that in mountainous regions, shallow, mid, and deep convective cores are sometimes mis-classified as elevated convective echo because radar beams at low elevation angle can be significantly attenuated by ground clutter.
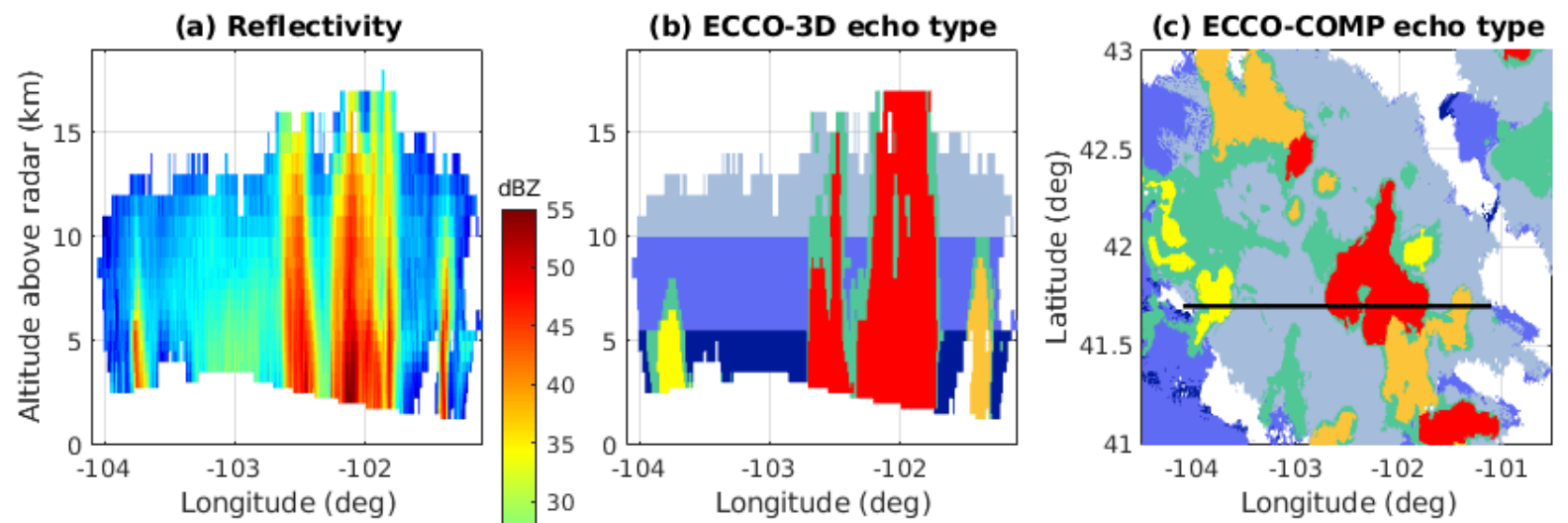

Conv deep
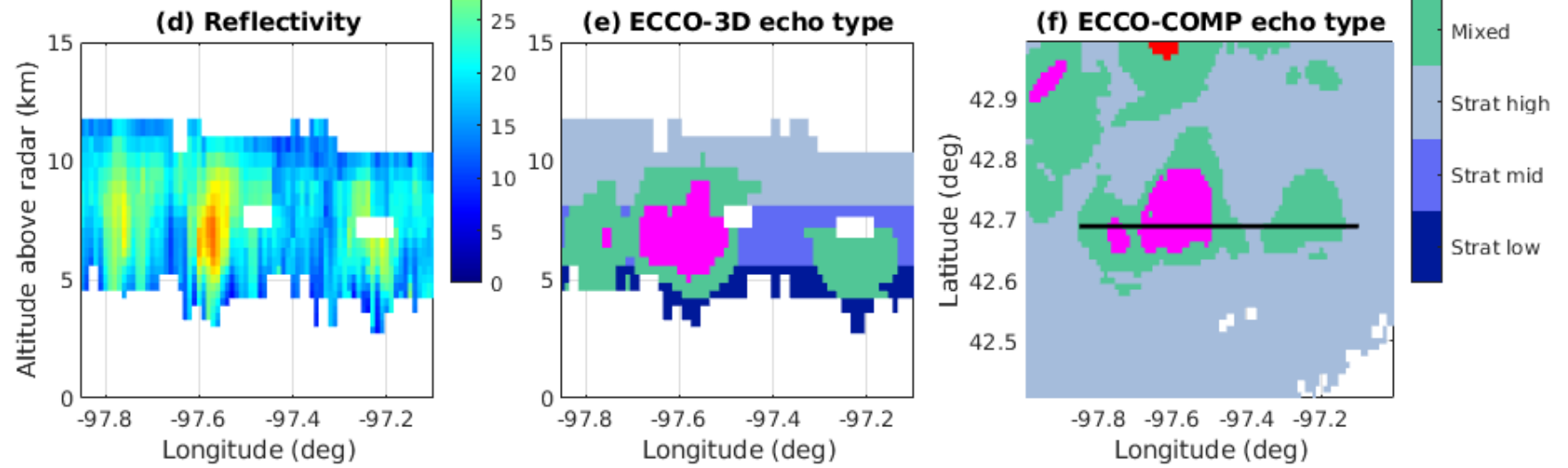

Fig. 3: Reflectivity (a,d), advanced ECCO-3D (b,e) and ECCO-COMP (see 3.5 below) (c,f) echo type for convective cells embedded in stratiform echo observed 2015-07-06 00:58 UTC (upper panels) and elevated convection observed 2015-06-22 09:56 UTC (lower panels) during PECAN. (a,b) and $(d, e)$ show vertical cross sections along the black lines in (c) and (f), respectively.

\subsection{ECCO-COMP: conversion to a composite 2D echo type classification}

The $3 \mathrm{D}$ classification is easily converted to a more traditional $2 \mathrm{D}$ composite on the horizontal dimensions, which we call ECCO-COMP. We number the categories in the 3D grid from lowest to highest according to their importance with the most important classification getting the highest number (see Appendix D). We can then collapse the 3D grid into a 2D grid simply by taking the maximum in the vertical column. In this way the classification deemed most important will be retained in the 2D classification. The order (from most important to least) is: convDeep, convMid, convShallow, convElev, mixed, stratHigh, stratMid, stratLow (displayed from top to bottom in the colorbar, Figure 3). We acknowledge that "importance" is subjective and may vary with intended use. We believe that the current order will be valuable for most users as it guarantees that convective echo will always be preserved, even if it is below stratiform echo. The position of convElev in the list is probably the most debatable. We decided to place it below the other convective classes for the following reasons: Elevated convection as, for example, studied 
in the PECAN field campaign (Fig. 3d-f) which is captured as convElev features will per definition not overlap with other convective features located below them. Cases where convElev features are located above other convective features therefore likely represent high level convective cloud elements which we assume to be of lesser interest to most users than convective features initiated near the surface. Examples of how the 3D classification translates to 2 dimensions are shown in Fig. 3c,f.

Note that throughout the rest of the paper we will mention ECCO echo types when we refer to algorithm output in general but will distinguish between ECCO-3D and ECCO-COMP when we specifically refer to $3 \mathrm{D}$ or composite echo types, respectively.

\subsection{Sensitivity of algorithm parameters to horizontal grid resolution}

SHY95 investigated the sensitivity of the partitioning results to the resolution of the Cartesian reflectivity grid and to the size and shape of the convective area surrounding a grid point designated as convective. In that paper the results were limited to a choice of 2 horizontal grid resolutions: $2 \mathrm{~km}$ and 4 $\mathrm{km}$.

In order to carry out a similar comparison for ECCO, we developed a test procedure in which the $0.01^{\circ}$ $(\sim 1 \mathrm{~km})$ horizontal resolution of the MRMS grid used in the PECAN analysis (Section 4.2) was progressively degraded by a factor of $2,3,4$ and 5 . An averaging procedure using a circular kernel was applied to compute the mean of the non-missing reflectivity values within a circle of radius 1.1 times the nominal grid resolution after degradation. This simulates an interpolation of the radar reflectivity onto a coarser grid.

Table 1: Sensitivity of algorithm parameters to horizontal grid resolution. PECAN case, 00:00 to 01:00 UTC on 2015-06-26.

\begin{tabular}{|l|l|l|l|l|l|}
\hline $\begin{array}{l}\text { Grid } \\
\text { resolution }\end{array}$ & texture_radius_km & texture_limit_high & $\begin{array}{l}\text { Convective } \\
\text { fraction }\end{array}$ & $\begin{array}{l}\text { Mixed } \\
\text { fraction }\end{array}$ & $\begin{array}{l}\text { Stratiform } \\
\text { fraction }\end{array}$ \\
\hline$\sim 1 \mathrm{~km}$ & $7.0 \mathrm{~km}$ & $30 \mathrm{dBZ}$ & 0.122 & 0.108 & 0.770 \\
\hline$\sim 2 \mathrm{~km}$ & $8.7 \mathrm{~km}$ & $30 \mathrm{dBZ}$ & 0.121 & 0.092 & 0.787 \\
\hline$\sim 3 \mathrm{~km}$ & $10.1 \mathrm{~km}$ & $30 \mathrm{dBZ}$ & 0.124 & 0.099 & 0.777 \\
\hline$\sim 4 \mathrm{~km}$ & $11.4 \mathrm{~km}$ & $30 \mathrm{dBZ}$ & 0.128 & 0.107 & 0.766 \\
\hline$\sim 5 \mathrm{~km}$ & $12.5 \mathrm{~km}$ & $30 \mathrm{dBZ}$ & 0.128 & 0.113 & 0.759 \\
\hline$\sim 2 \mathrm{~km}$ & $7.0 \mathrm{~km}$ & $28 \mathrm{dBZ}$ & 0.125 & 0.093 & 0.782 \\
\hline$\sim 3 \mathrm{~km}$ & $7.0 \mathrm{~km}$ & $26 \mathrm{dBZ}$ & 0.127 & 0.101 & 0.772 \\
\hline$\sim 4 \mathrm{~km}$ & $7.0 \mathrm{~km}$ & $23.7 \mathrm{dBZ}$ & 0.120 & 0.103 & 0.777 \\
\hline
\end{tabular}

The algorithm parameter most clearly dependent on the grid geometry is the radius used to compute the reflectivity texture (Section 3.1), texture_radius_km in Appendix B. For a given texture radius, as the grids become coarser the computed texture $(T D B Z)$ values will decrease. Since convectivity is designed to indicate the likelihood of convective echo, it should be independent of grid spacing. We can either increase the texture radius to keep $T D B Z$ constant, or compensate by adjusting the mapping from $T D B Z$ to 
convectivity (Fig. 2). The latter can be achieved by reducing the texure_limit_high parameter (Fig. 2, Appendix B) from the default value of $30 \mathrm{dBZ}$.

Using the $1 \mathrm{~km}$ MRMS resolution results as a baseline, we adjusted the algorithm parameters to keep the fraction of convective, mixed, and stratiform echo approximately constant. Since we are dealing with gridded data, there are jumps as the increasing radius encompasses extra grid locations. Table 1 shows the results for an active 1-hour period during PECAN. Progressively increasing the texture radius from 7.0 to $12.5 \mathrm{~km}$ as the grid resolution changes from 1 to $5 \mathrm{~km}$ allows us to keep the fraction of convective echo nearly constant while keeping texture_limit_high fixed at $30 \mathrm{dBZ}$. Alternatively if we keep the radius fixed at $7 \mathrm{~km}$, we can instead progressively decrease texture_limit_high from $30 \mathrm{dBZ}$ to $23.7 \mathrm{dBZ}$ as the grid resolution changes from $1 \mathrm{~km}$ to $4 \mathrm{~km}$. (The $5 \mathrm{~km}$ grid spacing is too coarse for a reasonable estimate of $T D B Z$ to be computed.)

\section{Validation using observations from the PECAN field project}

\subsection{Consistency check - regions of high reflectivity}

High reflectivity values are usually associated with convective regions, and some echo type classification algorithms use a threshold on reflectivity above which all echo is set to convective. As a first assessment on the performance of the ECCO algorithm we use the threshold of $42 \mathrm{dBZ}$ prescribed in Powell et al. (2016) to investigate if such high reflectivities are indeed classified as convective. We determine the distribution of reflectivity across the ECCO echo type categories for the PECAN field campaign. As intended, Fig. 4 shows that the majority (91.4\%) of these high reflectivity values are classified as convective while $7.5 \%$ are classified as mixed. Only $1.0 \%$ are classified as stratiform. This fundamental check gives us confidence in the algorithm's capability to correctly identify strong convective echoes.

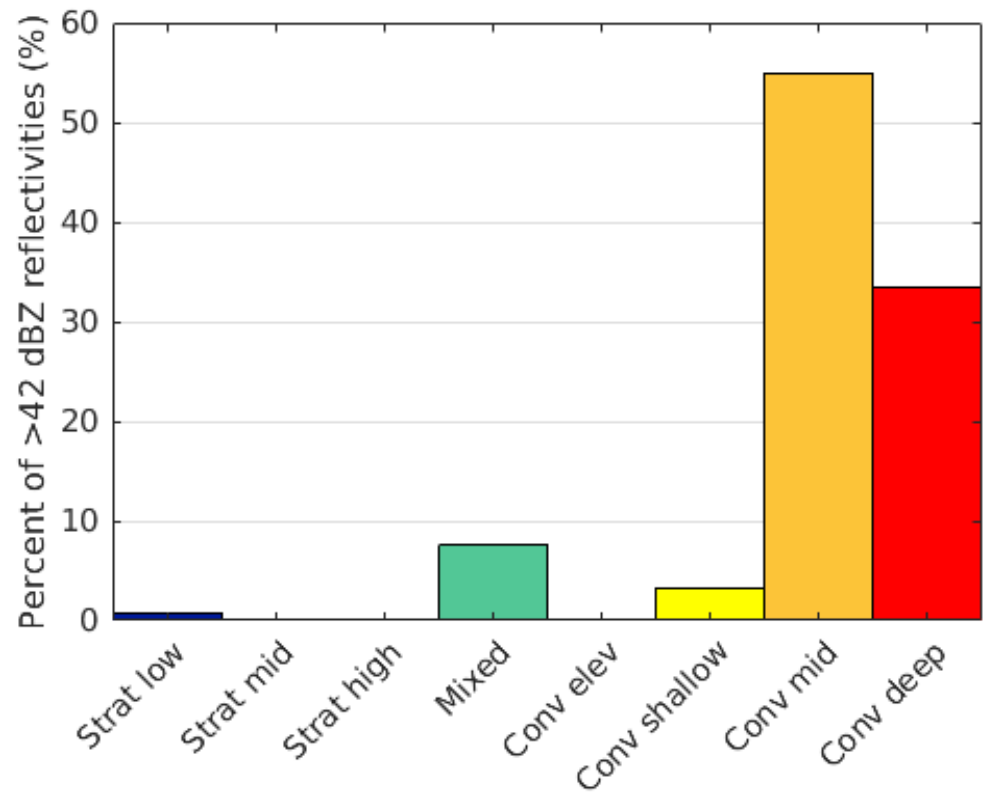

Fig. 4: Distribution of data points with reflectivities greater than $42 \mathrm{dBZ}$ over the echo type categories for the PECAN field campaign (1080 hours of radar data). 


\subsection{Quantitative comparison with lightning counts}

Lightning and convection are closely associated, especially for deeper convection (Zipser et al. 2006). Therefore lightning observations are useful for checking how well the algorithm separates convective from stratiform echo. In an isolated cumulonimbus cloud, lightning begins once the top of the convective feature reaches -10 to $-15{ }^{\circ} \mathrm{C}$ (Houze 2014). Therefore we expect the majority of the lightning to occur in areas with convMid, and especially convDeep, classifications. To test this hypothesis we use the ECCO-COMP categories derived from the MRMS radar product in the PECAN field campaign. The MRMS radar volumes were sampled at a 6 minute time resolution. Lightning data from the NLDN was also available for PECAN. The raw lightning counts were mapped onto a $2 \mathrm{D}$ Cartesian grid with the same geometry as the radar data. Counts were accumulated and stored every 5 minutes. These data sets are not precisely aligned in time, and the NEXRAD network on which the MRMS is based is not synchronized in time. Nevertheless with the time discrepancy between the radar and lightning data of the order of 5 minutes, we believe that this error in time does not significantly affect the comparison statistics.

(a) Area per echo type category

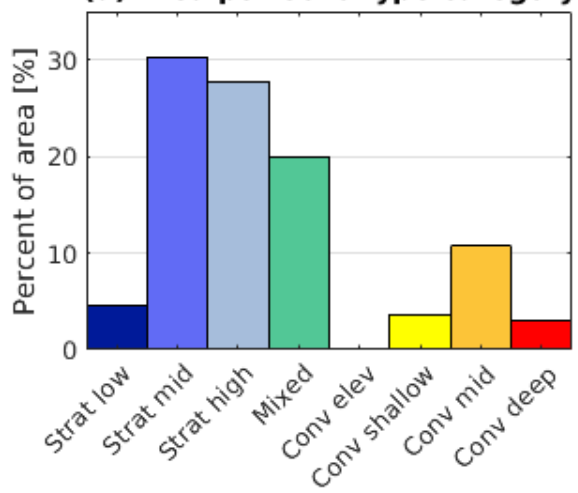

(b) Flashes per echo type category

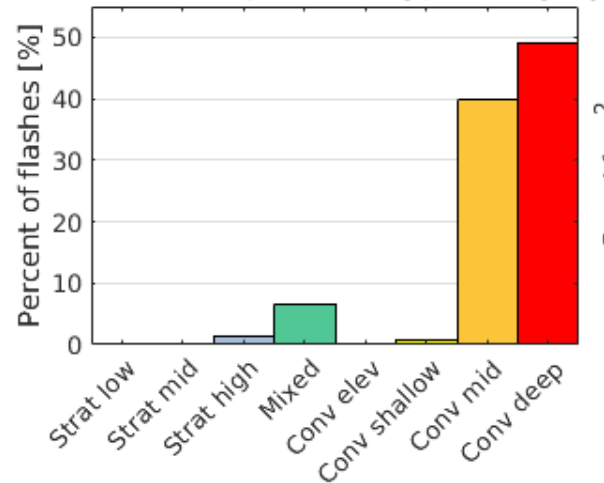

(d) Classification and flash counts

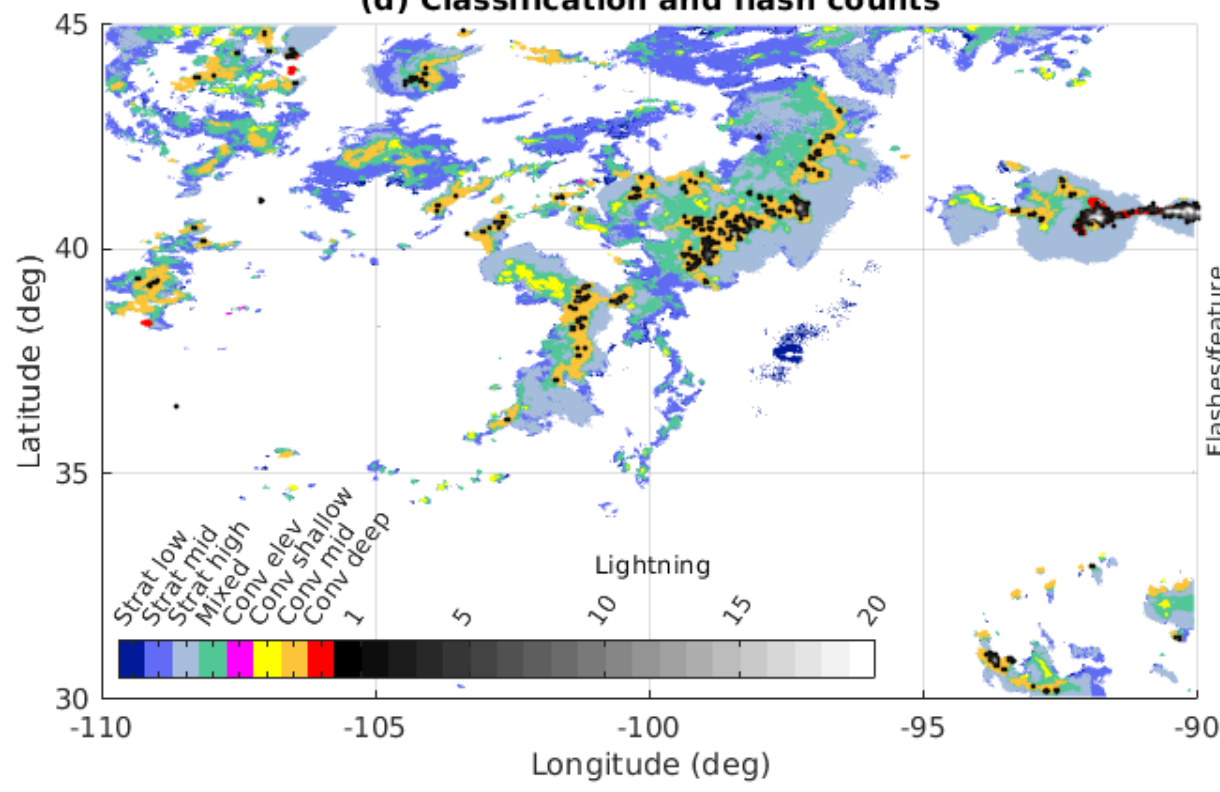

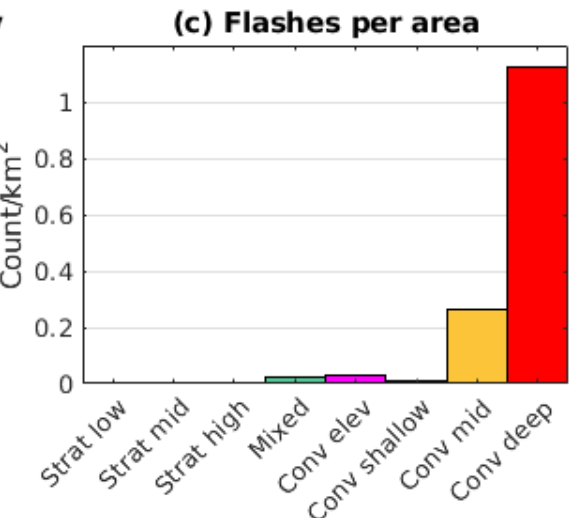

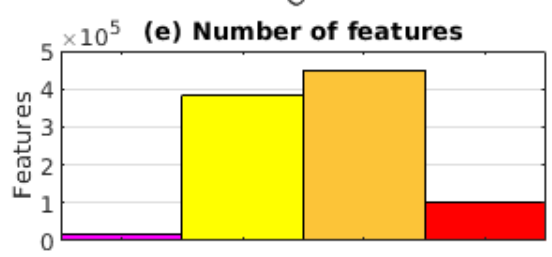

(f) Avg. flashes per feature

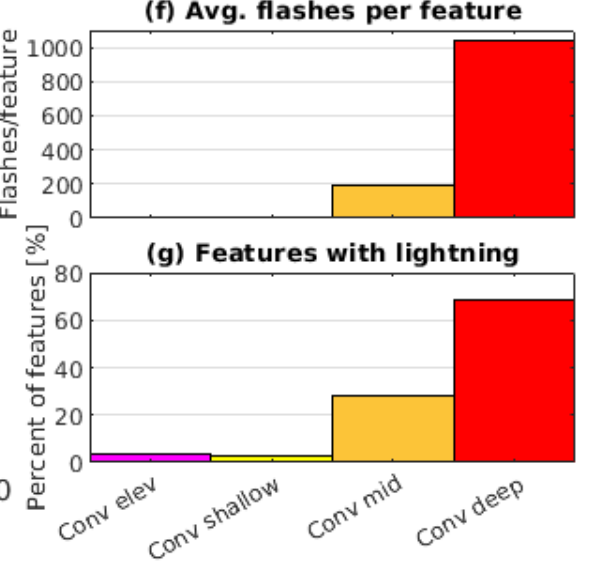

Fig. 5: Lightning analysis for the PECAN field campaign (2015-06-01 to 2015-07-16): (a) distribution of echo category by area, (b) flashes per category, (c) distribution of flashes per category, (d) example of 2D horizontal classification (color shading) and lightning density (gray shading) observed on 2015-06-11 02:26 UTC, (e) number of convective features, (f) average flash count per convective feature, and (g) percentage of convective features that exhibit lightning. 
First, to establish baseline statistics, we determine the distribution, by area, of the various echo type categories (Fig. 5a). stratMid is the most common, covering $30.3 \%$ of the active areas, followed by the stratHigh category with $27.7 \%$. Together, the three stratiform categories account for $62.6 \%$ of the active areas, and the convective categories $17.6 \%$, while the remaining $19.8 \%$ comprise the mixed category. These numbers are similar to those from previous studies: using TRMM data over the whole tropics, Schumacher and Houze (2003) found a stratiform area fraction of $75 \%$ over land while Romatschke and Houze $(2011,2013)$ found stratiform fractions of $46 \%$ over both the South Asian monsoon region and over South America.

Next we consider the relationship between the number of lightning counts and the echo categories. For each $(x, y)$ grid location we determine the ECCO-COMP echo type category, and the associated lighting count, using the lightning grid closest in time to the radar observations. We calculate the number of lightning flashes associated with each classification category (Fig. 5b). As expected, the convDeep (49.0\%) and convMid (39.9\%) categories dominate the distribution. When we calculate the average lightning density, convDeep dominates by more than a factor of four, with 1.12 flashes $\mathrm{km}^{-2}$. The convMid category follows with 0.26 flashes $\mathrm{km}^{-2}$ (Fig. 5c).

Using a clumping technique similar to that outlined in Appendix A, step 1, we identify contiguous features in the ECCO-COMP classifications at each time, and count their total number over the duration of the PECAN project (Fig. 5e). The convMid category has the highest number of features, with over 450,000, followed by the convShallow category with just over 381,000. There are fewer convDeep features, with only $\sim 100,000$, while convElev features occur $\sim 18,000$ times. When we calculate the average flash rate per feature, a different picture emerges. The convDeep category dominates with over 1000 flashes per feature (Fig. 5f), followed by the convMid category with about 190. When we count how many of these features exhibit at least one lightning flash, the convDeep category again dominates with $68.1 \%$ of the total (Fig. $5 \mathrm{~g}$ ), while the convMid category accounts for $27.7 \%$. The fact that such a high number of convDeep features exhibit lightning shows that the algorithm is not over-identifying deep convective features.

These results confirm our expectation that lightning is most often associated with deep convective features, followed by mid level convective features. The comparison of the echo type categories with lightning gives us confidence that the algorithm has considerable skill.

\subsection{Comparison with GPM DPR precipitation type}

The precipitation type classification algorithm that was originally developed for the TRMM PR is now used on the GPM DPR (Awaka et al. 1997, 2007, 2016). We refer to the GPM DPR precipitation type product as GPM PT. It has been extensively used in research studies and is generally considered to be reliable. GPM PT is provided on a horizontal $2 \mathrm{D}(\mathrm{x}, \mathrm{y})$ grid - at each point in the grid a precipitation type is assigned based on the vertical column of reflectivity observations above that point. We ran ECCO using the GPM DPR 3D reflectivity - here we will refer to the results of that run as GPM ECCO. We compared the results from GPM ECCO with GPM PT and also the ECCO categories obtained from the MRMS data from PECAN (which we call MRMS ECCO). 

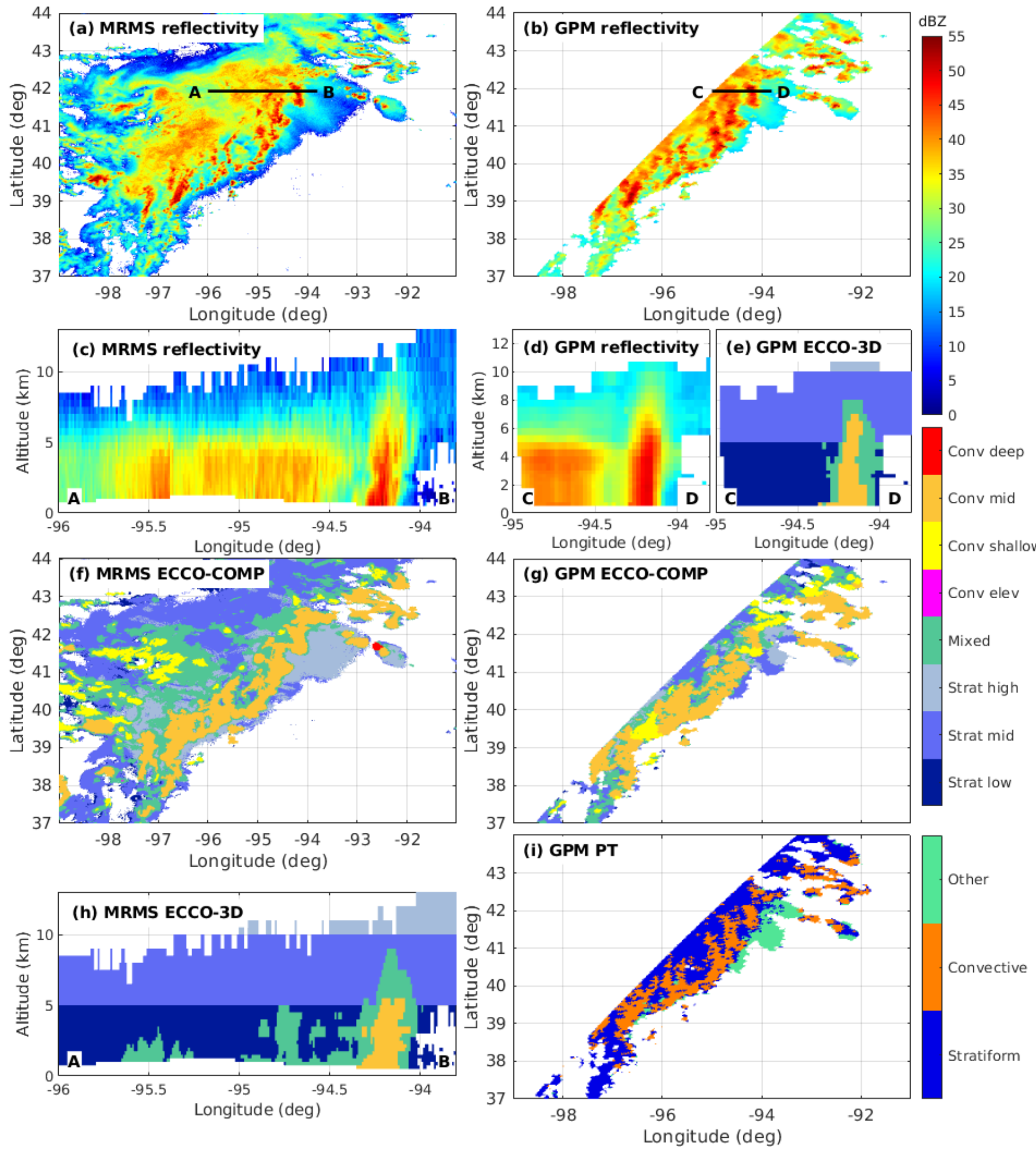

Fig. 6: MCS sampled on 2015-06-11 at 08:20 UTC over the PECAN region. Observations from the ground-based MRMS radar grid are shown in the left column and observations from the GPM DPR are shown on the right. $(a, b)$ Column maximum reflectivity, $(c)$ vertical cross section along line A-B in (a), (d) vertical cross section along line C-D in (b), (e) vertical cross section through GPM ECCO-3D along line C-D in (b), (f) MRMS and (g) GPM ECCO-COMP echo type, (h) vertical cross section through MRMS ECCO-3D along line A-B in (a), (i) GPM PT precipitation type. 
As described in Section 2.1, the original GPM DPR horizontal grid resolution is $5 \mathrm{~km}$, and we resampled using interpolation onto a $0.025^{\circ}$ lat/lon grid ( $2.5 \mathrm{~km}$ resolution). Because of this decreased resolution, the texture of reflectivity is somewhat smoother than for MRMS. We compensated for that by setting the parameter texture_limit_high (Section 3.6, Appendix B) to $25 \mathrm{dBZ}$ instead of $30 \mathrm{dBZ}$, resulting in convectivity from GPM that is comparable to that from MRMS.

ECCO-3D was applied to GPM DPR swaths collected over the PECAN region during the course of that project. Overall, GPM ECCO performed well as is shown in an example in Fig. 6. On June 11, 2015 at 08:20 UTC an MCS was located over the PECAN area and observed by the ground-based NEXRAD MRMS radar network (Fig. 6a). The MRMS ECCO results show a line of convMid echo with a trailing stratiform region containing some embedded convShallow echo (Fig. 6f). A vertical cross section confirms the observation of the active convection at the leading edge of the system (Fig. 6c) and the algorithm correctly identifies the trailing stratiform echo as mostly stratLow and stratMid (Fig. 6h).

GPM observed the leading edge of the MCS and the column maximum reflectivity closely matches the MRMS observations (Fig. 6a,b). The vertical cross section (Fig. 6d) at the same location confirms the MRMS observations (Fig. 6c). GPM ECCO (Fig. 6e,g) produces similar results to MRMS ECCO (Fig. 6f,h) and identifies the same convMid line, although some regions are classified convShallow. A comparison with GPM PT (Fig. 6i) shows similar patterns of convective and stratiform regions. However, the GPM PT convective rain type regions are somewhat smaller than the convective regions from GPM ECCO.

To compare GPM ECCO-COMP with GPM PT we investigate how the three GPM PT precipitation types (convective, stratiform, and other) are distributed among the GPM ECCO-COMP categories (Fig. 7). For the GPM PT stratiform category $48.6 \%$ are classified in the GPM ECCO stratiform categories (Fig. 7a) and $35.6 \%$ are classified as GPM ECCO mixed. The remaining $15.8 \%$ are classified in the GPM ECCO convective categories. Most of the GPM PT stratiform points that are classified as GPM ECCO convective can likely be attributed to the widening of the convective regions in ECCO as described in the previous paragraph.

Analysis of the GPM PT convective precipitation type shows that $68.0 \%$ of data points are classified as GPM ECCO convective and $19.8 \%$ are classified as GPM ECCO mixed. Only $12.2 \%$ are classified as GPM ECCO stratiform. The GPM PT 'other' precipitation type is mostly classified as GPM ECCO stratiform $(78.1 \%)$ and GPM ECCO mixed (14.5\%) while $7.4 \%$ is classified as GPM ECCO convective. It is not surprising that most of the 'other' precipitation type points are classified as stratiform and mixed when we consider that ECCO does not have an 'other' category, and that ECCO identifies convective regions first and then classifies the remainder as stratiform or mixed. Overall the two algorithms compare very well. GPM ECCO gives similar results to the well established GPM PT algorithm but has the additional benefit of providing a vertically resolved classification and additional sub-categories. 

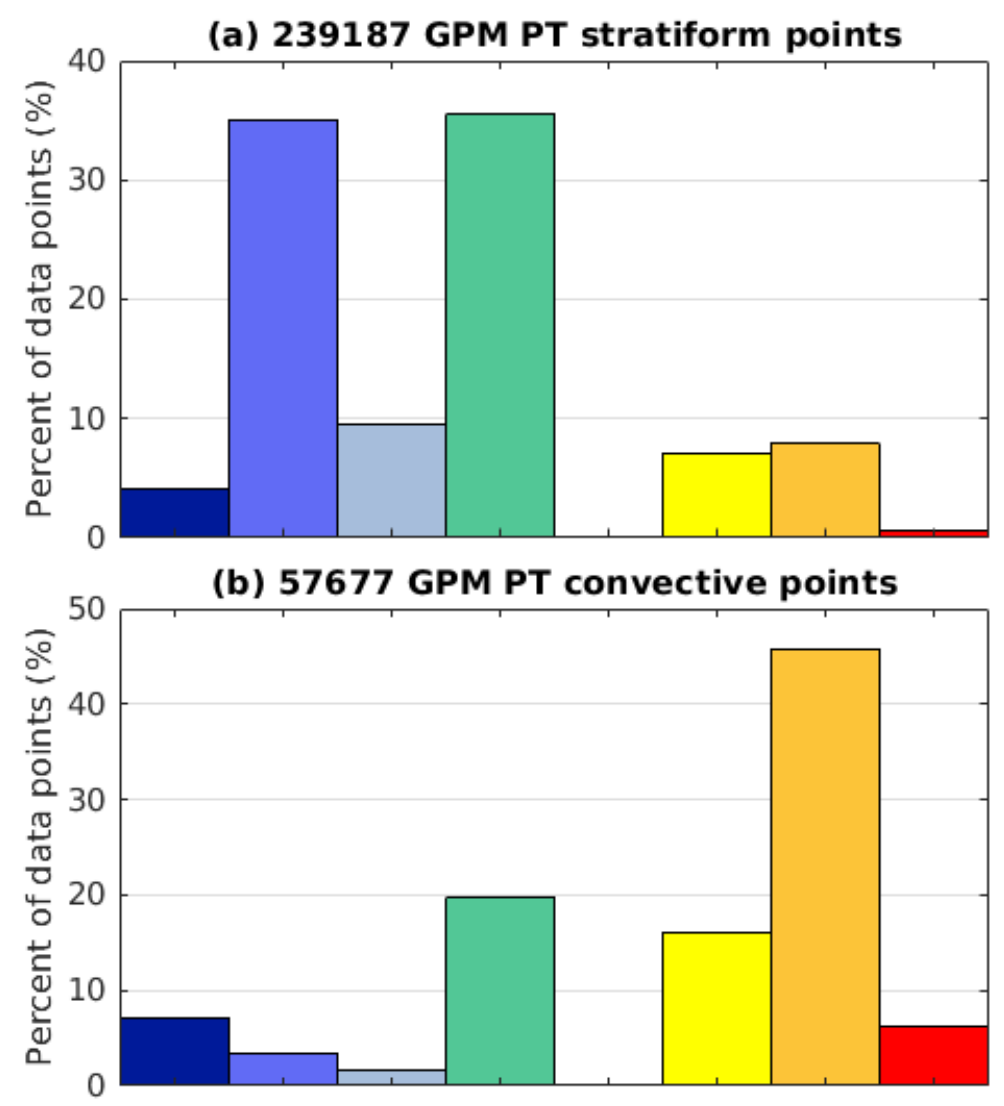

(c) 75534 GPM PT other points

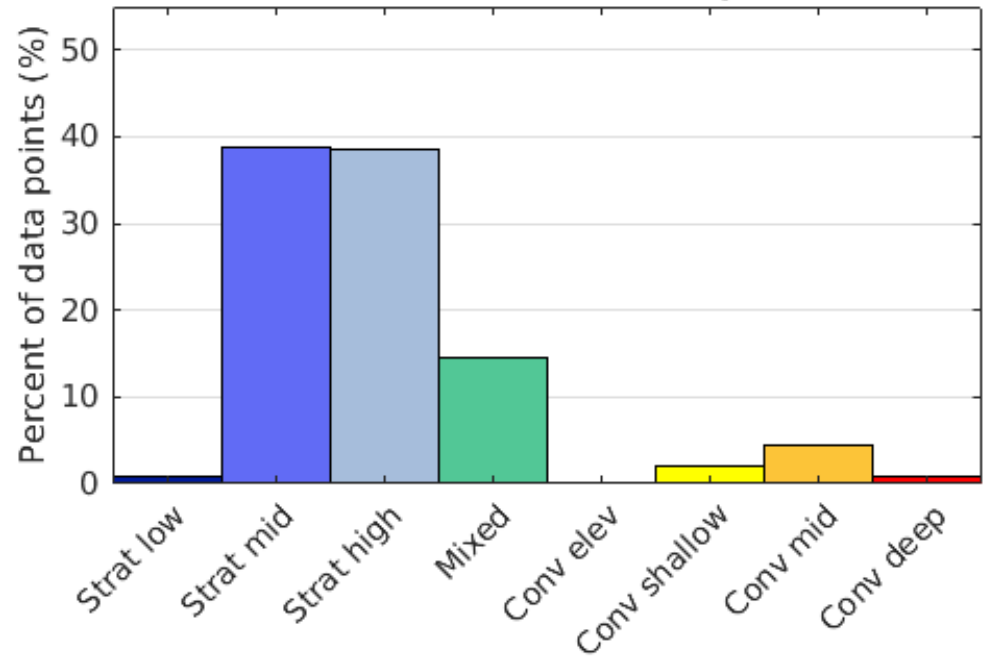

Fig. 7: Percentage of the GPM PT precipitation type data points per GPM ECCO-COMP category for (a) stratiform, (b) convective, and (c) other.

\section{Applying ECCO to geographically-diverse data sets}

\subsection{North America: NEXRAD MRMS}

The readily accessible and high quality NEXRAD MRMS radar grid is a prime candidate on which to test ECCO in a wider setting. ECCO was run on the MRMS CONUS grid for several months of 2021. The algorithm clearly identifies embedded convection and makes it easy to track convective cells visually in time. The highlighting of convective features makes the classification an interesting input field for storm 
tracking algorithms such as TITAN (Thunderstorm Identification Tracking Analysis Nowcasting, https://github.com/NCAR//rose-titan, Dixon and Wiener 1993) or TINT (TINT is not TITAN, https://github.com/openradar/TINT).
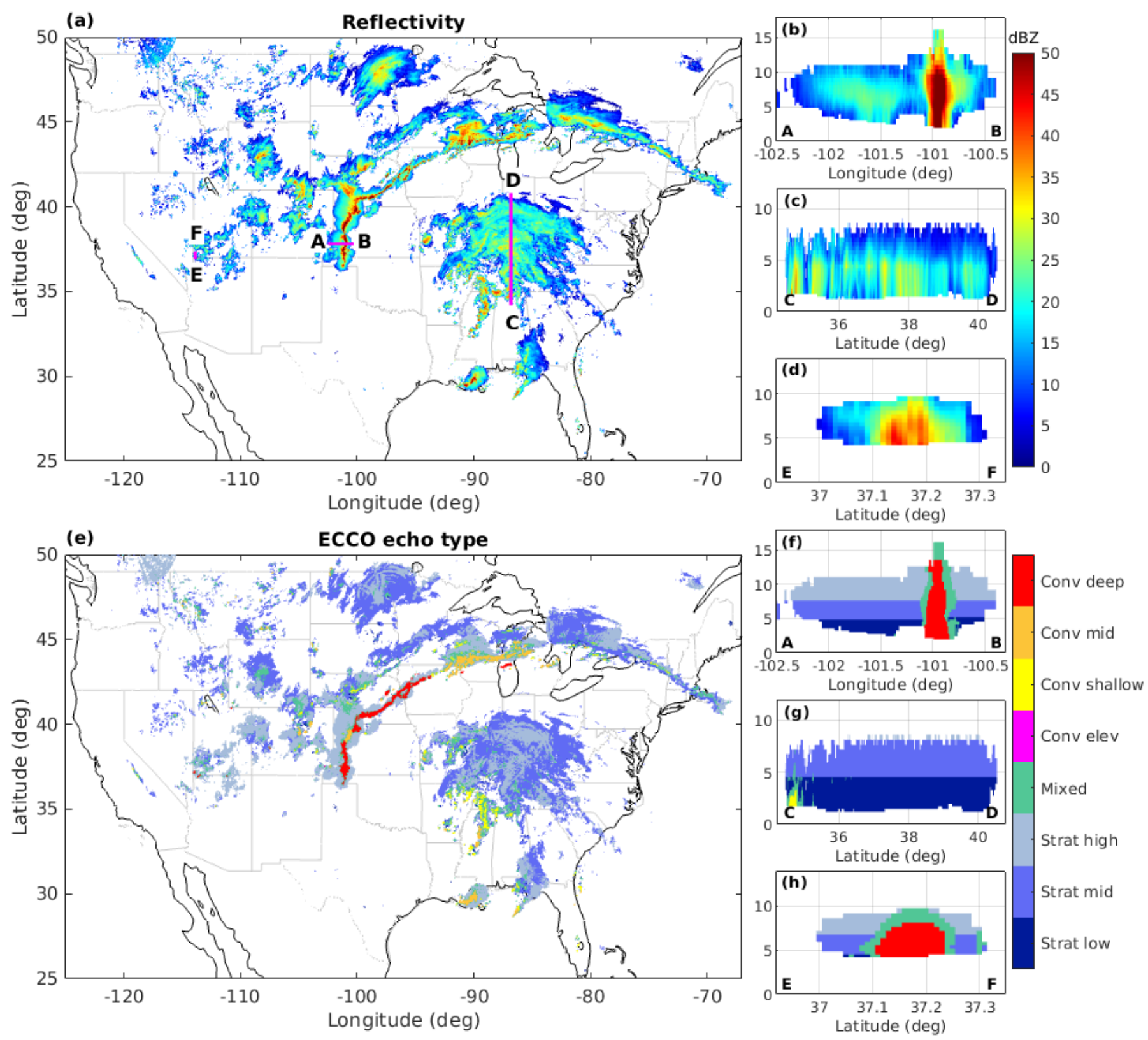

Fig. 8: MRMS radar grid from 2021-05-03 01:07 UTC. (a) Column maximum reflectivity, reflectivity vertical cross sections along pink lines labeled A-B (b), C-D (c), and E-F (d) in (a). ECCO-COMP echo type (e) and vertical cross sections of ECCO-3D echo type ( $f$ to $h$ ).

As an example, a variety of meteorological phenomena occurred across the US on 2021-05-03. The most striking feature visible in the MRMS grid from 01:08 UTC (Fig. 8a,e) shows a line of convection arching from the central US to the northeast coast. The line has three distinct areas: deep convective echo was observed over the western plains, echo just west of and over the Great Lakes area reached mid levels, and echo east of the Great Lakes was mainly stratiform. These areas represent three distinct stages in the life cycle of convective systems (Houze 2014). While some convective activity was prevalent throughout the previous day May 2, on May 3 it was intensified by solar heating which led to the triggering of new 
convective cells in the respective local afternoon hours: first in the east 20:00 UTC, then in the Great Lakes area 21:00 UTC, and then followed by the western plains 22:00 UTC (not shown). At 01:08 (Fig. 8) the eastern systems are already in the late, stratiform stages of their life cycle, while the Great Lakes systems are at their mature stage where convective cells lose depth but broaden to later form stratiform areas. The systems in the west are still young and vigorous. A vertical cross section along the pink line labeled A-B in Fig. 8a shows the extreme strength and depth of these convective cells (Fig. 8b) which are consequently labeled as convDeep (Fig. 8f). Several tornado touch down reports were associated with these deep convective storms.

An aging MCS, observed over the Southeast, consists mostly of stratiform echo with some smaller scale convective features at its southern edge. A vertical cross section along the line labeled C-D in Fig. 8a shows bright band echo which is classified as stratiform, and a convective cell near $\mathrm{C}$, which is labeled as convShallow (Fig. 8c,g).

Small echo cells are evident over the mountains in the western US which are likely caused by diurnal heating of the elevated terrain. Some of these cells are deep, such as the cell shown in the vertical cross section along the line labeled E-F in Fig. 8a, which captures a small evening thunderstorm (Fig. 8d,h). Since the algorithm does not operate on one specific vertical level, as many of the previous algorithms do, it is robust in complex terrain.

\subsection{United Arab Emirates and Australia}

So far, we have only shown cases from the US. To investigate if ECCO performs well on 3D radar observations from other parts of the world, we tested it on data from the United Arab Emirates and Australia (Fig. 9).

An MCS was observed over the Persian Gulf on 2017-03-24 at 03:36 UTC (Fig. 9, left panels). The deep convective cores along the coast of the United Arab Emirates reached altitudes of over $15 \mathrm{~km}$. Strong bright band echo with values up to $40 \mathrm{dBZ}$ was observed over the Gulf, which was classified as stratiform, as expected (Fig. 9c,g).

A line of flood-producing convective echo reaching mid levels was observed on 2021-03-13 at 11:30 UTC stretching from the coast just south of Sydney, Australia, to the northwest. Again, the convective cores are clearly identified, demonstrating the skill of the algorithm for different radar grids and geographic areas. 


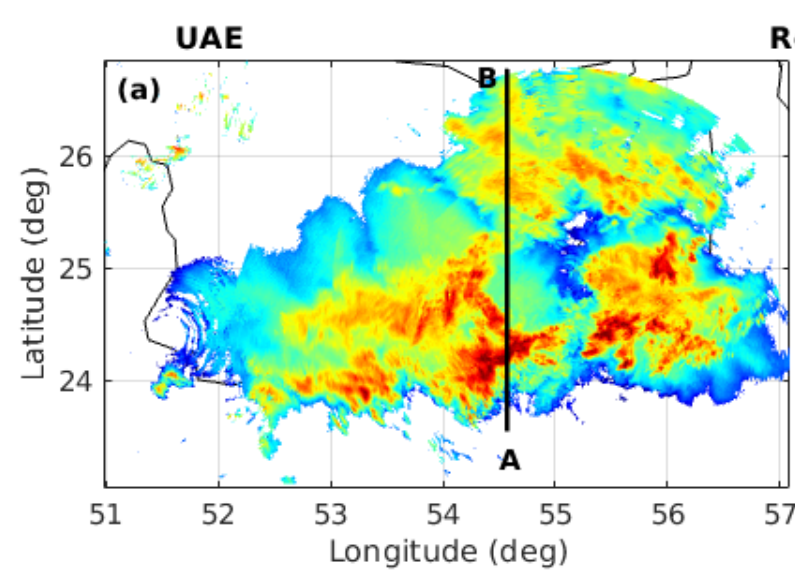

Reflectivity

Australia
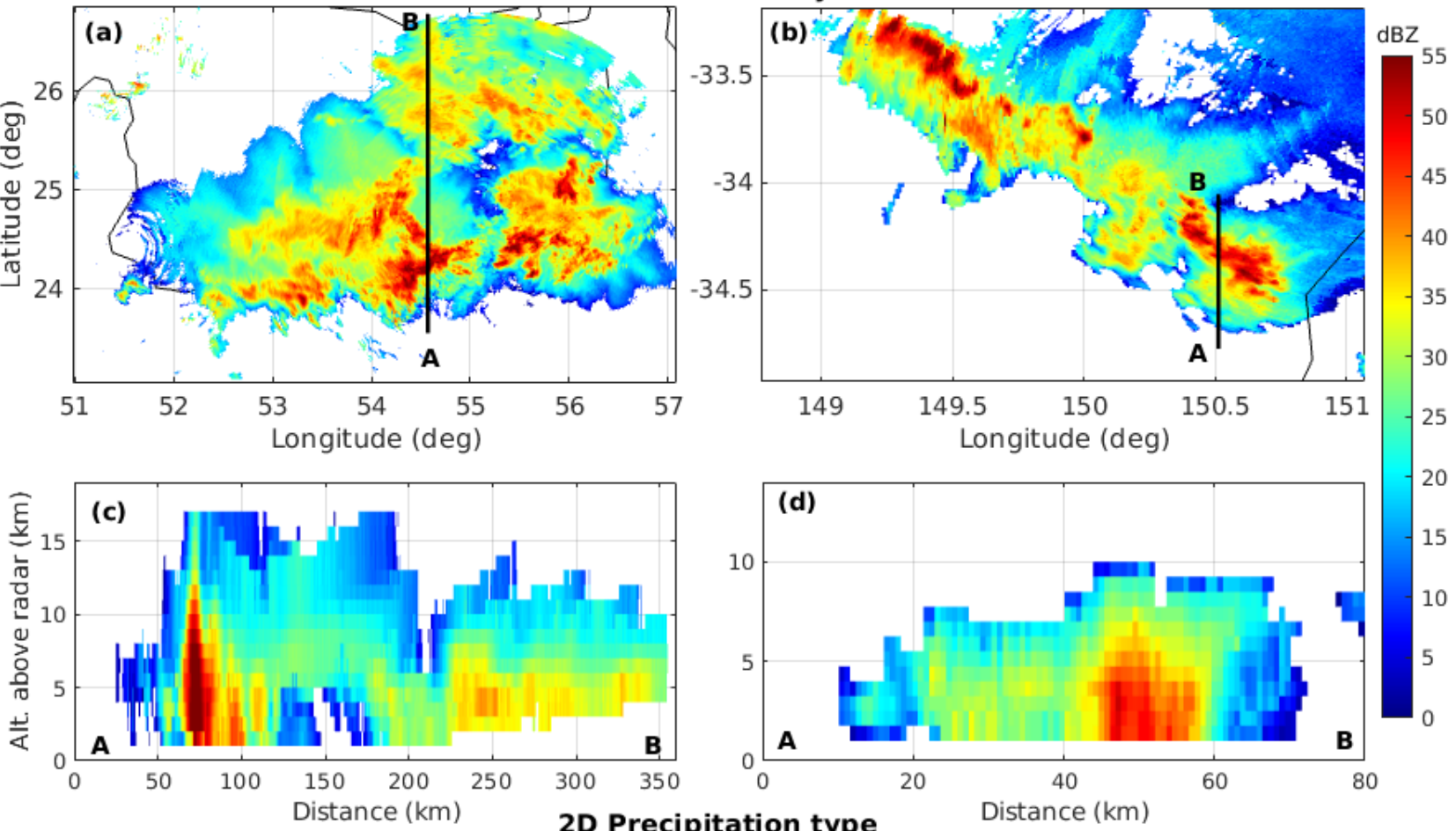

pitation type
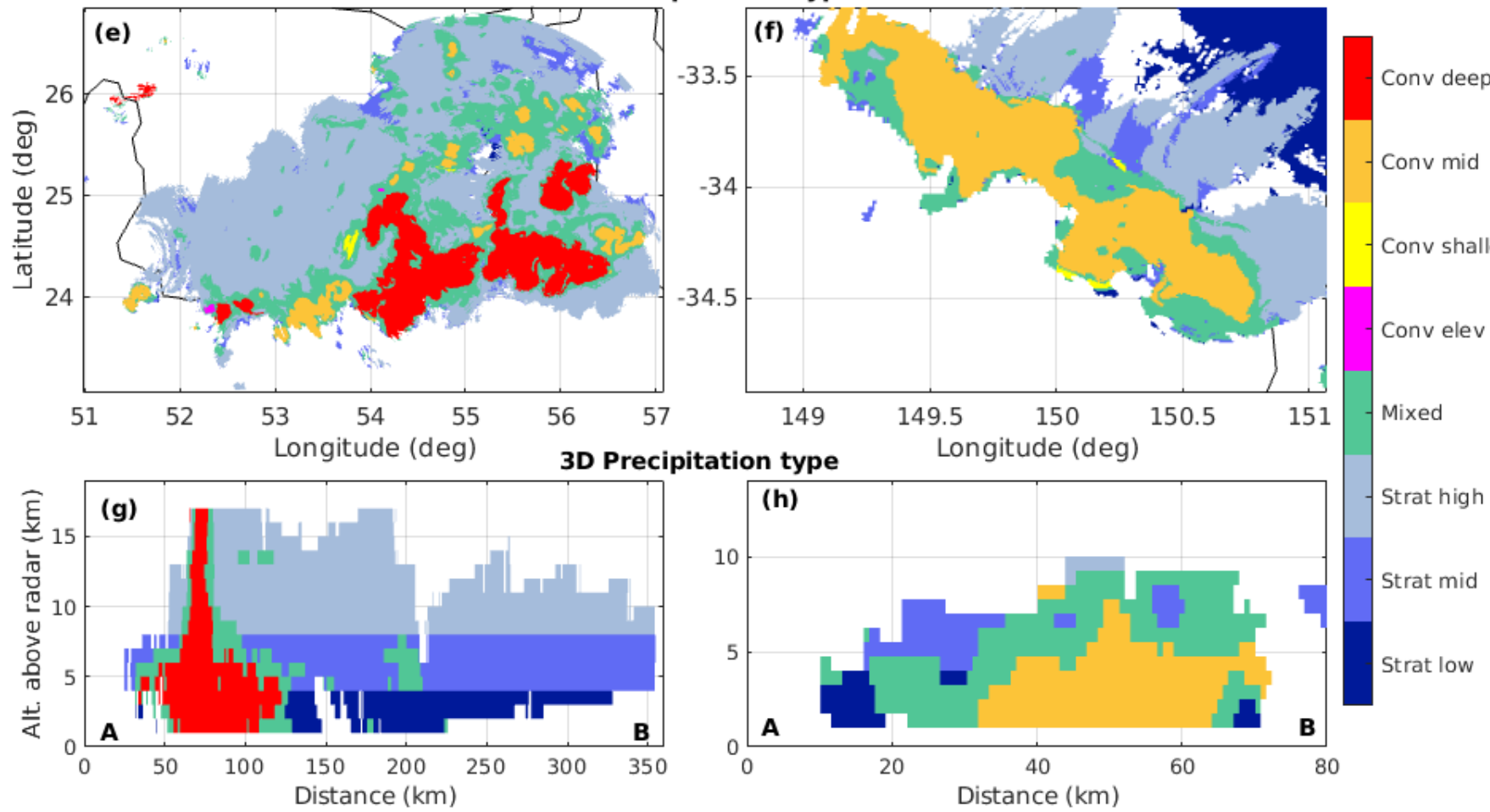

Fig. 9: Reflectivity (a-d), ECCO-COMP (e,f) and ECCO-3D (g,h) echo types for cases observed 2017-03-24 03:36 UTC over the Persian Gulf (left) and 2021-03-13 11:30 UTC near Sydney, Australia (right). (c,d) and ( $g, h)$ show vertical cross sections along the black lines in $(a, b)$. 


\subsection{Europe: a test on the 2D OPERA mosaic}

The European radar network mosaic only provides 2D data, of column-maximum reflectivity, using a grid resolution of $2 \mathrm{~km} \times 2 \mathrm{~km}$. Since the ECCO algorithm calculates convectivity on the horizontal axes, it can be expected to still have skill in 2D for classifying convective and stratiform echo regions.
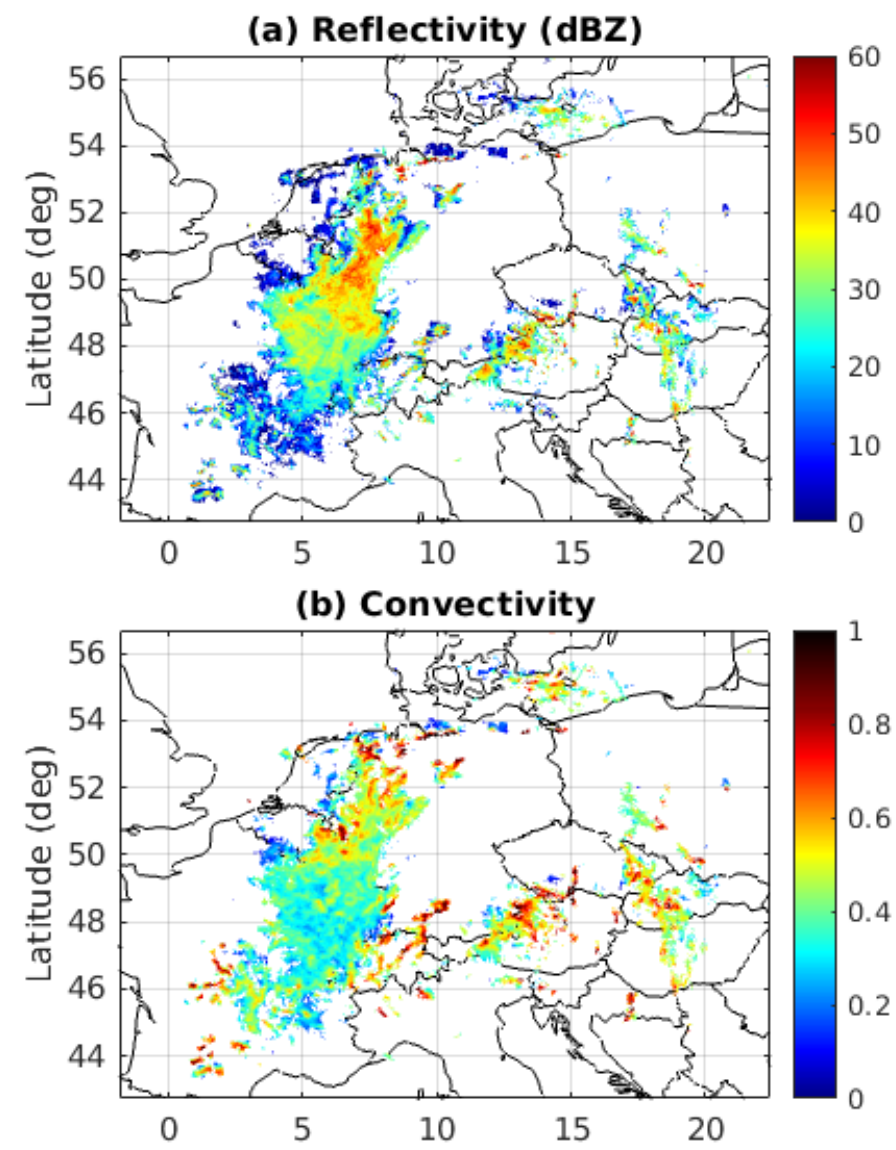

(c) Basic precipitation type

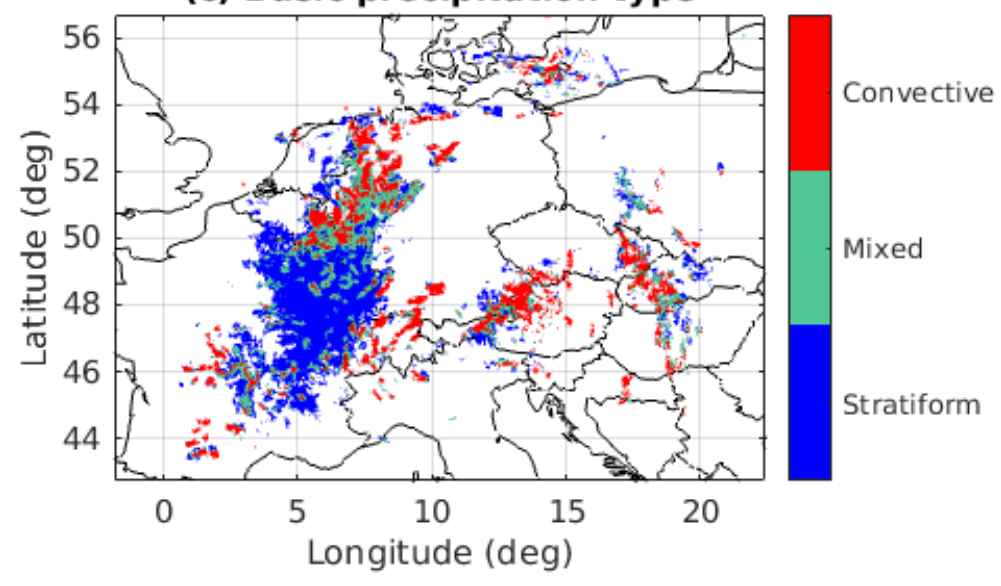

Fig. 10: (a) Reflectivity, (b) convectivity, and (c) basic ECCO echo type derived from OPERA observations from 2021-07-14 at 15:05 UTC.

ECCO was tested on data from the summer of 2021 and Fig. 10 shows an example captured on 2021-07-14 at 15:05 UTC. At that time a low pressure system extended from southern France all the way 
to the North Sea. It remained almost stationary for several days and caused catastrophic flooding in northern Europe, particularly in Germany, Belgium, and the Netherlands. Severe storms associated with the same low pressure system also caused flooding in the Alps and central Europe. Over 220 deaths were reported.

Since the vertical dimension is not available, ECCO only performs the basic classification. Convective regions are clearly identified and coincide with the major flooding regions of Germany, Belgium, and the Netherlands. The severe storms over the Alps are captured at the border of Austria and Germany, and over Switzerland. Another cluster of severe storms extends from Hungary over Slovakia to the Czech Republic. A large stratiform area over eastern France was associated with significant but less severe precipitation than in the convectively dominated regions.

One note on applying ECCO on the OPERA grid - because of the coarser grid resolution of $2 \mathrm{~km}$, as compared to the MRMS grid resolution of $1 \mathrm{~km}$, the texture radius was increased from $7 \mathrm{~km}$ to $8.5 \mathrm{~km}$. See Section 3.6, and Appendix B.

\section{Conclusions}

We have developed a new algorithm (ECCO) for separating convective and stratiform echoes in 3D Cartesian grids, using radar reflectivity as the primary observed field. This work builds on previous techniques, particularly Steiner et al. (1995). A major difference is the formulation of the reflectivity texture, which is based on the standard deviation of the square of the reflectivity over a horizontal circle. We compensate for edge gradient effects before computing the texture. This texture field is robust and skillful in identifying the convective areas. We introduce the notion of convectivity which is derived from the reflectivity texture by a linear transformation that yields convectivity as a normalized field with values between 0 and 1 , with higher values indicating the likelihood of convective features. It provides a 3D quantitative measure of the convective vs. stratiform nature of each grid cell. The mapping from texture to convectivity can be readily adjusted to account for different grid resolutions, because the texture is smoother for grids with lower spatial resolution.

In its basic mode, ECCO produces a 3D grid of categories signifying stratiform, convective, or mixed echoes. In the advanced mode temperature observations are used to refine these categories to indicate low/shallow, mid, high/deep and elevated features, again in three dimensions, significantly increasing the information content of the product.

We applied ECCO to the 3D MRMS mosaic during the 2015 PECAN field project, and used lightning data to demonstrate its skill. As expected, the vast majority of lightning flashes occur in regions where ECCO classified deep convective features. We also applied it to GPM DPR data gathered during PECAN, and showed that ECCO works well using GPM reflectivity and that the results are similar to the GPM DPR precipitation type product. We also ran ECCO on the MRMS grid for the full CONUS, and on radar mosaics from the UAE, Australia, and Europe. In all of these cases the algorithm appears to perform with skill. A distinct version of ECCO was developed for vertically pointing radars (ECCO-V) which is described in Romatschke and Dixon (2022).

Through all the different examples described above, ECCO has proven to be easy to use but adaptable and robust. We believe that ECCO will prove useful to scientists and operational weather services. It provides not only the first vertically resolved qualitative echo type classification, but also 
introduces convectivity - a quantitative measure of how convective each 3D grid point is. We expect applications to be developed to explore the full potential of the convectivity concept.

\section{Acknowledgements}

This paper is based upon work supported by the National Center for Atmospheric Research, which is a major facility sponsored by the National Science Foundation under Cooperative Agreement No. 1852977. We thank Matthias Steiner, Tammy Weckwerth, and Stacy Brodzik for valuable comments on the manuscript.

\section{Data Availability Statement}

ECCO input and output data for PECAN are available in the EOL Field Data Archive at https://doi.org/10.5065/D6M043SK (UCAR/NCAR-Earth Observing Laboratory 2016). The NEXRAD 3D MRMS data over the full CONUS (Zhang et al. 2005) was downloaded in real-time using the Unidata Local Data Manager (LDM, https://doi.org/10.5065/D64J0CT0). The radar mosaic from the Sydney region of south-east Australia was obtained via personal communication from Rod Potts at the Australian Bureau of Meteorology (BOM) in Melbourne. The radar mosaic from the United Arab Emirates (UAE) was obtained via personal communication with Karel DeWaal at the UAE National Center of Meteorology (NCM). OPERA data (Huuskonen et al. 2014; Saltikoff et al. 2019) was accessed through the EUMETNET OPERA data center ODYSSEY http://dcpcodpi.meteo.fr/.

Temperature data from the NOAA Rapid Update Cycle (RUC) model for PECAN was obtained via the LDM. For the Sydney and UAE cases, we used publicly-available sounding data from the on-line archive at the University of Wyoming (http://weather.uwyo.edu/upperair/sounding.html).

NLDN lightning data (Orville et al. 2002) was downloaded in real-time using the LDM. 


\section{Appendix A. Clumping convective regions into 3D objects}

As mentioned in Section 3.4, it is useful to analyze convective regions as objects, using the clumping method introduced by Dixon and Wiener (1993). A clump consists of a contiguous region in the 3D Cartesian grid, with data values exceeding a specified convectivity threshold. We proceed in three steps which are illustrated in Fig. A1. This example shows stratiform precipitation with embedded convective cells observed during PECAN.

Step 1 performs clumping in 3D on the convectivity field, using a threshold of 0.5 , which is the value that separates convective from mixed echo (Fig. 2). It identifies contiguous convective features. Note that only grid cells that share a common border are considered connected while grid cells touching only at a corner are considered separate. Clumps identified in step 1 are shown in red (and overlain by yellow) as a horizontal composite in Fig. A1a. We call these large clumps. The advanced classification algorithm (Section 3.4) can be applied using the large clumps. However, the volume of a large clump can be significant, especially in cases where convective cells merge together. It is advantageous to separate merged convective cells that only slightly touch each other before applying the advanced classification, as one cell may reach to deep levels while the other may only be mid or shallow. To separate large clumps that are only joined in a minor way we perform steps 2 and 3.

Step 2 takes each of the large clumps in turn, and computes sub-clumps at a higher convectivity threshold of 0.65 . For speed and simplicity we carry out step 2 in $2 \mathrm{D}$ instead of 3D, using the column-maximum field of convectivity. The identified sub-clumps are shown in yellow in Fig. A1a. If a large clump contains only one sub-clump, the large clump is used unchanged. The sub-clumps are then examined for validity. If the cumulative total area of all sub-clumps within a large clump is less than 0.33 of the area of the large clump, we ignore the sub-clumps and use the large clump as it is. This is the most frequent situation. If, on the other hand, the cumulative sub-clump area meets the 0.33 fraction criterion, we examine each of the sub-clumps for validity. An individual sub-clump is considered valid if its area exceeds a minimum value $\left(2 \mathrm{~km}^{2}\right)$ and a minimum fraction of the large clump (0.02). We call the valid sub-clumps small clumps and they are shown in Fig. A1c.

To ultimately provide an echo type classification for all grid points in the original convective feature, in step 3 the small clumps are progressively grown until they either meet each other or reach the original boundary of the large clump (Fig. A1d). The resulting grown clumps are kept as separate entities during the application of the advanced classification. The growing operation is carried out in $2 \mathrm{D}$, but the grown clumps are restored to $3 \mathrm{D}$ objects by extending their boundaries into the vertical dimension. 


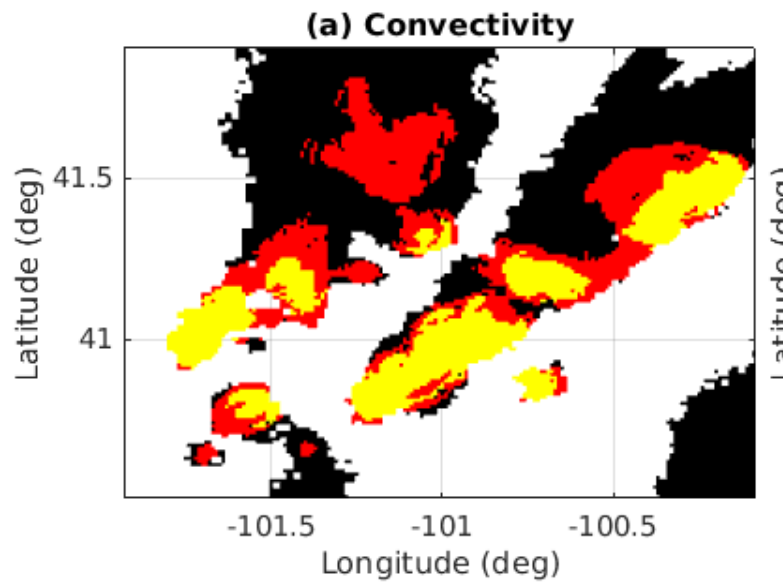

(c) Small clumps

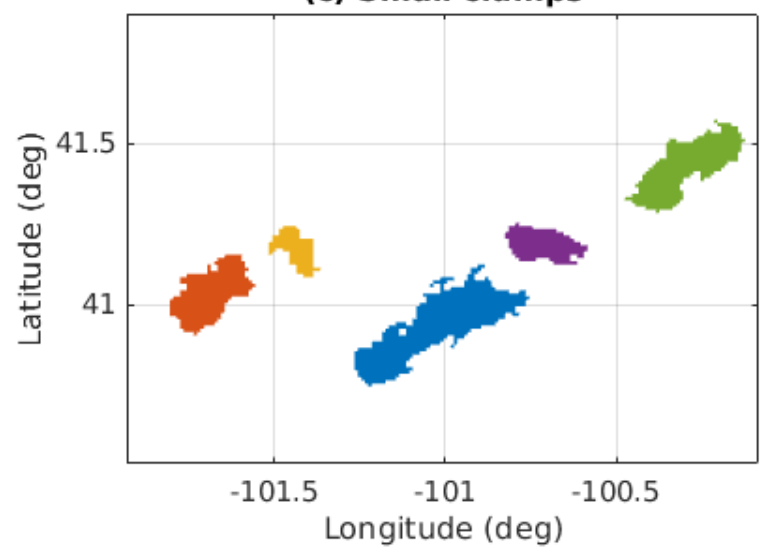

(e) Echo type single thresh

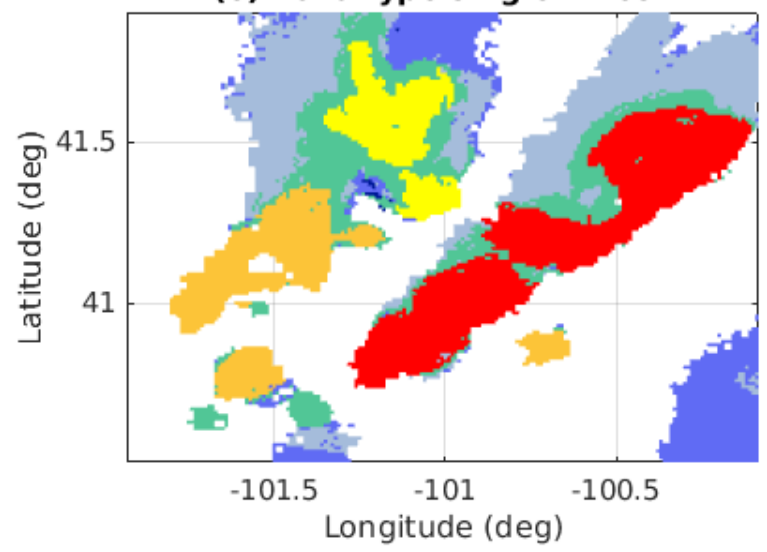

(b) Reflectivity (dBZ)

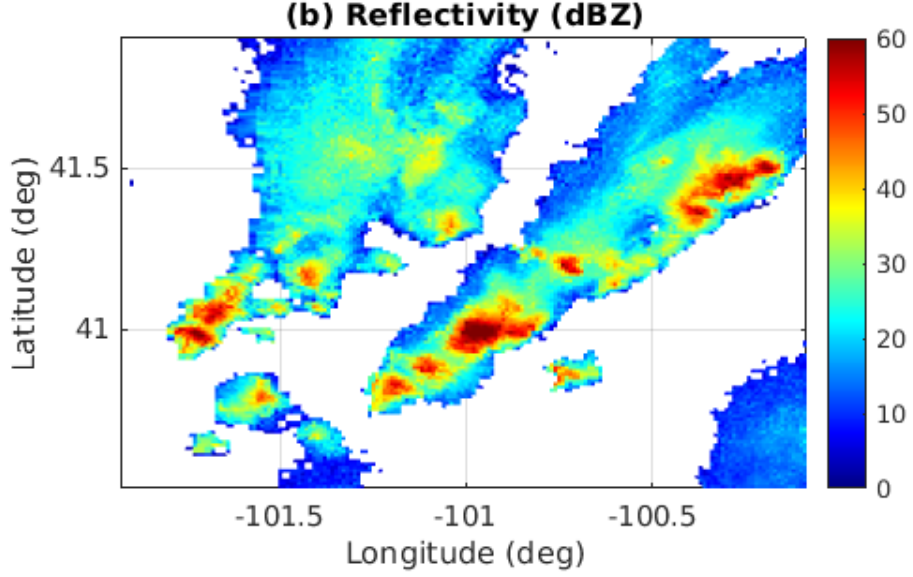

(d) Grown clumps

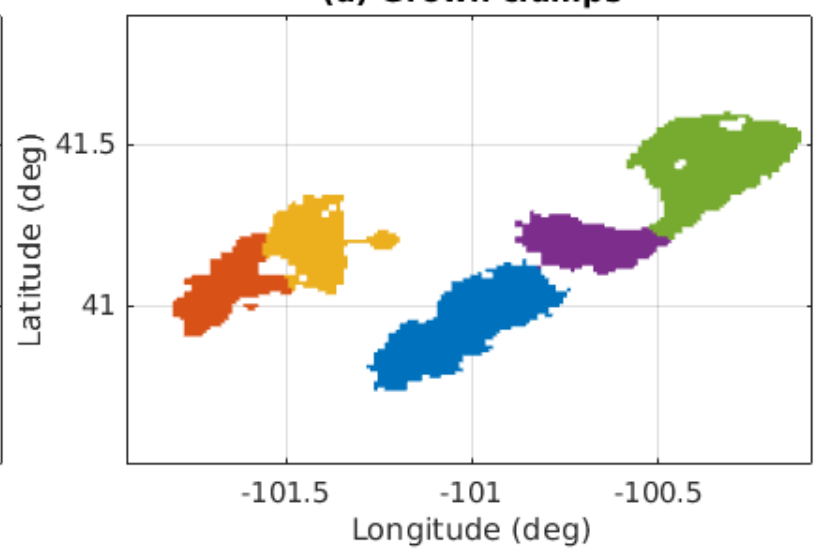

(f) Echo type dual thresh

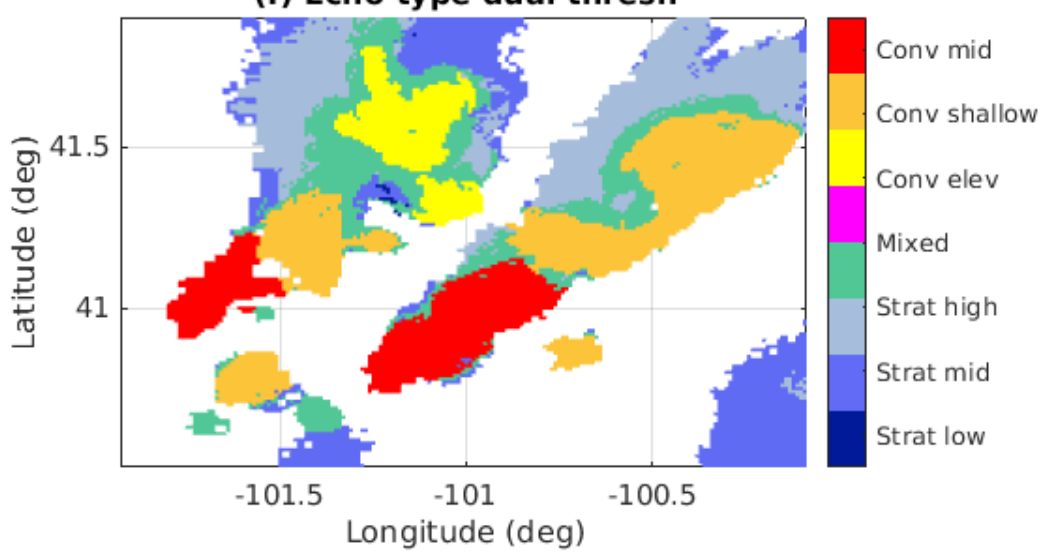

Fig. A1: Precipitation system observed 2015-06-14 at 23:50 UTC during PECAN. (a) Column-maximum convectivity. Black: less than 0.5 (stratiform and mixed echo); red: between 0.5 and 0.65 (large clumps), yellow: exceeds 0.65 (sub-clumps). (b) Reflectivity. (c) Small clumps. (d) Grown clumps. (e) Advanced ECCO-COMP echo type obtained after step 1, and (f) after steps 2 and 3.

Applying steps 2 and 3 has been found to be effective in splitting up clumps that combine convective entities that logically should be separate. Fig. A1e shows the echo type categories computed using the clumps after step 1, while Fig. A1f shows the categories after splitting the clumps up using steps 2 and 3. They illustrate how the dual threshold helps to break up the clumps into more logical objects. 


\section{Appendix B. Algorithm parameters}

The following is the list of parameters used by ECCO, along with their default values. These are the parameters used by the Ecco application in LROSE, at https://github.com/NCAR/lrose-core/tree/master/codebase/apps/radar/src/Ecco

Table B1: ECCO parameters and default values.

\begin{tabular}{|c|c|c|}
\hline Parameter & Default value & Comment \\
\hline \multicolumn{3}{|c|}{ Basic algorithm (Sections 3.1 to 3.3 ) } \\
\hline min_valid_dbz & $0 \mathrm{dBZ}$ & $\begin{array}{l}\text { Reflectivity below this threshold is set to } \\
\text { missing. }\end{array}$ \\
\hline base_dbz & $\begin{array}{l}\text { Suggested values are: } \\
\text { S-, C- and X-band: } 0 \mathrm{dBZ} \\
\text { Ka-band: }-10 \mathrm{dBZ} \\
\text { W-band: }-20 \mathrm{dBZ}\end{array}$ & $\begin{array}{l}\text { Lower bound of reflectivity useful for } \\
\text { identifying convective echo. Ka-band } \\
\text { and W-band radars operate in the Mie } \\
\text { scattering region and will have useful } \\
\text { negative reflectivity values (Ellis and } \\
\text { Vivekanandan 2011: Zhang 2019). }\end{array}$ \\
\hline texture_radius_km & $\begin{array}{l}7 \mathrm{~km} \text {. } \\
\text { See also Table } 1 \text {, Section } \\
\text { 3.6. }\end{array}$ & $\begin{array}{l}\text { Radius around a grid point for computing } \\
\text { the active fraction and TDBZ. }\end{array}$ \\
\hline min_valid_fraction_for_texture & 0.25 & $\begin{array}{l}\text { A grid point is marked active if the } \\
\text { fraction of grid points with non-missing } \\
\text { reflectivity, within the texture radius and } \\
\text { in that plane, exceeds this lower bound. }\end{array}$ \\
\hline min_valid_fraction_for_fit & 0.67 & $\begin{array}{l}\text { If the active fraction is less than this, the } \\
2 D(x, y) \text { linear fit to reflectivity is not } \\
\text { performed prior to computing texture. }\end{array}$ \\
\hline texture_limit_low & 0.0 & $\begin{array}{l}\text { Texture value for mapping to a } \\
\text { convectivity value of } 0.0 \text {. Convectivity } \\
\text { varies linearly from } 0 \text { to } 1 \text {, between } \\
\text { texture_limit_low and texture_limit_high. }\end{array}$ \\
\hline texture_limit_high & $\begin{array}{l}30.0 \text { for grid resolution of } 1 \\
\mathrm{~km} . \\
\text { See also Table } 1 \text {, Section } \\
\text { 3.6. }\end{array}$ & $\begin{array}{l}\text { Texture value for mapping to a } \\
\text { convectivity value of } 1.0 \text {. See also } \\
\text { texture_limit_low. }\end{array}$ \\
\hline min_convectivity_for_convective & 0.5 & $\begin{array}{l}\text { Convectivity threshold for convective } \\
\text { echo. Lower bound. (In the advanced } \\
\text { classification, this is the primary } \\
\text { threshold for the clumping step 1.) }\end{array}$ \\
\hline max_convectivity_for_stratiform & 0.4 & $\begin{array}{l}\text { Convectivity threshold for stratiform } \\
\text { echo. Upper bound. } \\
\text { If between } \\
\text { min_convectivity_for_convective and } \\
\text { max_convectivity_for_stratiform, then } \\
\text { mixed. }\end{array}$ \\
\hline
\end{tabular}




\begin{tabular}{|c|c|c|}
\hline \multicolumn{3}{|l|}{ Advanced algorithm (Section 3.4) } \\
\hline shallow_threshold_temp & $0{ }^{\circ} \mathrm{C}$ & $\begin{array}{l}\text { Temperature threshold for separating } \\
\text { shallow/low categories from mid } \\
\text { categories (freezing level). }\end{array}$ \\
\hline Alternative: shallow_threshold_height & $\mathrm{km}$ & $\begin{array}{l}\text { Height threshold for separating } \\
\text { shallow/low categories from mid } \\
\text { categories, if model-based temperature } \\
\text { field is not available. }\end{array}$ \\
\hline deep_threshold_temp & $-25^{\circ} \mathrm{C}$ & $\begin{array}{l}\text { Temperature threshold for separating the } \\
\text { mid categories from the deep/high } \\
\text { categories (divergence level). }\end{array}$ \\
\hline Alternative: deep_threshold_height & $\mathrm{km}$ & $\begin{array}{l}\text { Height threshold for separating mid } \\
\text { categories from the deep/high } \\
\text { categories if model-based temperature } \\
\text { field is not available. }\end{array}$ \\
\hline min_valid_volume_for_convective & $20 \mathrm{~km}^{3}$ & $\begin{array}{l}\text { Convective features smaller than this } \\
\text { are marked mixed. }\end{array}$ \\
\hline min_vert_extent_for_convective & $1 \mathrm{~km}$ & $\begin{array}{l}\text { Convective features with less vertical } \\
\text { extent than this are marked mixed. }\end{array}$ \\
\hline \multicolumn{3}{|l|}{ Clumping (Appendix A) } \\
\hline clumping_use_dual_thresholds & TRUE & $\begin{array}{l}\text { Option to use dual thresholds for } \\
\text { clumping. If FALSE, only step } 1 \text { is run. If } \\
\text { TRUE, steps } 2 \text { and } 3 \text { are also run. }\end{array}$ \\
\hline clumping_secondary_convectivity & 0.65 & $\begin{array}{l}\text { Convectivity threshold for small clumps. } \\
\text { Lower bound. }\end{array}$ \\
\hline all_subclumps_min_area_fraction & 0.33 & $\begin{array}{l}\text { If the sum of the areas of all sub-clumps } \\
\text { within one large clump is less than this, } \\
\text { the large clump is used. }\end{array}$ \\
\hline each_subclump_min_area_fraction & 0.02 & $\begin{array}{l}\text { If the area of a sub-clump exceeds this } \\
\text { fraction it is considered valid. }\end{array}$ \\
\hline each_subclump_min_area_km2 & $2 \mathrm{~km}^{2}$ & $\begin{array}{l}\text { If the area of a sub-clump exceeds this it } \\
\text { is considered valid. }\end{array}$ \\
\hline \multicolumn{3}{|c|}{ Designating advanced echo types to clumps (Section 3.4, Appendix C) } \\
\hline min_conv_fraction_for_deep & 0.05 & $\begin{array}{l}\text { The min fraction of a clump above the } \\
\text { divergence level for the clump to be } \\
\text { designated convDeep. }\end{array}$ \\
\hline min_conv_fraction_for_shallow & 0.95 & $\begin{array}{l}\text { The min fraction of a clump below the } \\
\text { freezing level for the clump to be } \\
\text { designated convShallow. }\end{array}$ \\
\hline max_shallow_conv_fraction_for_elevated & 0.05 & $\begin{array}{l}\text { The max fraction of a clump below the } \\
\text { freezing level for the clump to be } \\
\text { designated convElev. }\end{array}$ \\
\hline
\end{tabular}




\begin{tabular}{|l|l|l|}
\hline max_deep_conv_fraction_for_elevated & 0.25 & $\begin{array}{l}\text { The max fraction of a clump above the } \\
\text { divergence level for the clump to be } \\
\text { designated convElev. }\end{array}$ \\
\hline min_strat_fraction_for_strat_below & 0.90 & $\begin{array}{l}\text { The min fraction of the area, } \\
\text { immediately below a clump, which is } \\
\text { designated stratiform, for the clump to } \\
\text { be designated as having stratiform } \\
\text { below. }\end{array}$ \\
\hline
\end{tabular}

\section{Appendix C. Logic for computing the advanced 3D echo type}

For the parameters used in this appendix, see Appendix B.

To determine the advanced echo types (Section 3.4), for each convective feature (clump) identified, we compute the following properties:

- Volume $\left(\mathrm{km}^{3}\right)$.

- Volume fraction above the divergence level (fracDeep).

- Volume fraction between the divergence level and freezing level (fracMid).

- Volume fraction below the freezing level (fracShallow).

- Fraction of the area of the clump that has stratiform grid points immediately below (fracStratBelow).

- Vertical extent $(\mathrm{km})$ - the height of the uppermost grid location in a clump minus the height of the lowermost grid location. If the clump is contained with 1 vertical level the vertical extent is 0 .

We then apply the following logic to determine the echo type of the clump:

- if the volume is less than min_valid_volume_for_convective: mixed.

- else if the vertical extent is less than min_vert_extent_for_convective: mixed.

- else if fracShallow is less than max_shallow_conv_fraction_for_elevated, and fracStratBelow exceeds min_strat_fraction_for_strat_below (i.e. there is stratiform echo immediately below) then:

o if fracDeep is less than max_deep_conv_fraction_for_elevated: convElev.

- else: mixed

- else if fracShallow exceeds min_conv_fraction_for_shallow: convShallow.

- else if fracDeep exceeds min_conv_fraction_for_deep: convDeep.

- else: convMid.

To categorize the remaining (i.e. non-convective) active grid points, with convectivity of less than min_convectivity_for_convective, we apply the following logic:

- if the convectivity is greater than max_convectivity_for_stratiform: mixed.

- else if the altitude of the grid point is less than the freezing level: stratLow.

- else if the altitude of the grid point is larger than the divergence level: stratHigh.

- else: stratMid. 


\section{Appendix D. Echo type integer values}

ECCO assigns integer values to each echo type, designed in such a way that computing the maximum in a vertical column converts the full 3D product to a useful 2D product. The following table lists the integer values assigned to each echo type.

Table D1: Integer values for echo types.

\begin{tabular}{|l|l|l|}
\hline Echo type & Integer value & Comment \\
\hline MISSING & 0 & No echo. \\
\hline STRATIFORM_LOW & 14 & Low-level stratiform, below freezing level. \\
\hline STRATIFORM & 15 & Generic stratiform, basic algorithm or 2D data. \\
\hline STRATIFORM_MID & 16 & Mid-level stratiform, between freezing and divergence levels. \\
\hline STRATIFORM_HIGH & 18 & Upper-level stratiform, above divergence level. \\
\hline MIXED & 25 & Not clearly stratiform or convective. \\
\hline CONVECTIVE_ELEVATED & 32 & Above freezing level with mixed or stratiform below. \\
\hline CONVECTIVE_SHALLOW & 34 & Mostly below freezing level. \\
\hline CONVECTIVE & 35 & Generic convective, basic algorithm or 2D data. \\
\hline CONVECTIVE_MID & 36 & $\begin{array}{l}\text { Significant echo above freezing level, but not above the } \\
\text { divergence level. }\end{array}$ \\
\hline CONVECTIVE_DEEP & 38 & Significant echo above the divergence level. \\
\hline
\end{tabular}




\section{References}

American Meteorological Society, Stratiform - Glossary of Meteorology Available online: https://glossary.ametsoc.org/wiki/Stratiform (accessed on 2 April 2021).

American Meteorological Society, Convective Cloud - Glossary of Meteorology Available online: https://glossary.ametsoc.org/wiki/Convective_cloud (accessed on 2 April 2021).

Anagnostou, E. N., 2004: A convective/stratiform precipitation classification algorithm for volume scanning weather radar observations. Meteorol. Appl., 11, 291-300, https://doi.org/10.1017/S1350482704001409.

Awaka, J., T. Iguchi, H. Kumagai, and K. Okamoto, 1997: Rain type classification algorithm for TRMM Precipitation Radar. Geoscience and Remote Sensing, 1997. IGARSS '97. Remote Sensing - A Scientific Vision for Sustainable Development., 1997 IEEE International, Vol. 4 of, Geoscience and Remote Sensing, 1997. IGARSS '97. Remote Sensing - A Scientific Vision for Sustainable Development., 1997 IEEE International, 1633-1635.

Awaka, J., T. Iguchi, and K. Okamoto, 2007: Rain Type Classification Algorithm. Measuring Precipitation From Space: EURAINSAT and the Future, V. Levizzani, P. Bauer, and F.J. Turk, Eds., Advances In Global Change Research, Springer Netherlands, 213-224.

— - M. Le, V. Chandrasekar, N. Yoshida, T. Higashiuwatoko, T. Kubota, and T. Iguchi, 2016: Rain Type Classification Algorithm Module for GPM Dual-Frequency Precipitation Radar. J. Atmospheric Ocean. Technol., 33, 1887-1898, https://doi.org/10.1175/JTECH-D-16-0016.1.

Biggerstaff, M. I., and S. A. Listemaa, 2000: An Improved Scheme for Convective/Stratiform Echo Classification Using Radar Reflectivity. J. Appl. Meteorol. Climatol., 39, 2129-2150, https://doi.org/10.1175/1520-0450(2001)040<2129:AISFCS>2.0.CO;2.

Dixon, M., and G. Wiener, 1993: TITAN: Thunderstorm Identification, Tracking, Analysis, and Nowcasting-A Radar-based Methodology. J. Atmospheric Ocean. Technol., 10, 785-797, https://doi.org/10.1175/1520-0426(1993)010<0785:TTITAA>2.0.CO;2.

Ellis, S. M., and J. Vivekanandan, 2011: Liquid water content estimates using simultaneous S and Ka band radar measurements. Radio Sci., 46, https://doi.org/10.1029/2010RS004361.

Geerts, B., and Coauthors, 2017: The 2015 Plains Elevated Convection at Night Field Project. Bull. Am. Meteorol. Soc., 98, 767-786, https://doi.org/10.1175/BAMS-D-15-00257.1.

Haynes, J. M., 2018: CloudSat 2C-PRECIP-COLUMN Data Product Process Description and Interface Control Document.

http://www.cloudsat.cira.colostate.edu/sites/default/files/products/files/2C-PRECIP-COLUMN_PDIC D.P1_R05.rev1_.pdf,.

— , T. S. L'Ecuyer, G. L. Stephens, S. D. Miller, C. Mitrescu, N. B. Wood, and S. Tanelli, 2009: Rainfall retrieval over the ocean with spaceborne W-band radar. J. Geophys. Res. Atmospheres, 114, https://doi.org/10.1029/2008JD009973.

Houze, R. A., 1997: Stratiform precipitation in regions of convection: A meteorological paradox? Bull. Am. Meteorol. Soc., 78, 2179-2196.

_., 2014: Cloud Dynamics. Academic Press,. 
Howard, L., 1803: On the Modifications of Clouds. J. Taylor, London,.

Hubbert, J. C., M. Dixon, and S. M. Ellis, 2009: Weather Radar Ground Clutter. Part II: Real-Time Identification and Filtering. J. Atmospheric Ocean. Technol., 26, 1181-1197, https://doi.org/10.1175/2009JTECHA1160.1.

Huuskonen, A., E. Saltikoff, and I. Holleman, 2014: The Operational Weather Radar Network in Europe. Bull. Am. Meteorol. Soc., 95, 897-907, https://doi.org/10.1175/BAMS-D-12-00216.1.

Igel, M. R., A. J. Drager, and S. C. van den Heever, 2014: A CloudSat cloud object partitioning technique and assessment and integration of deep convective anvil sensitivities to sea surface temperature. $J$. Geophys. Res. Atmospheres, 119, 10515-10535, https://doi.org/10.1002/2014JD021717.

Iguchi, T., and R. Meneghini, 2016: GPM DPR Ku Precipitation Profile 2A 1.5 hours 5 km V06. Greenbelt, $M D$, Goddard Earth Sciences Data and Information Services Center (GES DISC), https://doi.org/10.5067/GPM/DPR/Ku/2A/06.

Kessinger, C., S. Ellis, and J. Van Andel, 2003: The Radar Echo Classifier: A Fuzzy Logic Algorithm for the WSR-88D. 3rd Conference on Artificial Applications to the Environmental Science, American Meteorological Society, Long Beach, CA https://ams.confex.com/ams/annual2003/techprogram/paper_54946.htm (Accessed January 24, 2022).

Kuang, Z., and D. L. Hartmann, 2007: Testing the Fixed Anvil Temperature Hypothesis in a Cloud-Resolving Model. J. Clim., 20, 2051-2057, https://doi.org/10.1175/JCLI4124.1.

Lang, S., W.-K. Tao, J. Simpson, and B. Ferrier, 2003: Modeling of Convective-Stratiform Precipitation Processes: Sensitivity to Partitioning Methods. J. Appl. Meteorol. Climatol., 42, 505-527, https://doi.org/10.1175/1520-0450(2003)042<0505:MOCSPP>2.0.CO;2.

Michael Dixon, and B. Javornik, 2016: Lidar Radar Open Software Environment (LROSE) Core Software. UCAR/NCAR - Earth Observing Laboratory, https://doi.org/10.5065/60HZ-RY38.

Orville, R. E., G. R. Huffines, W. R. Burrows, R. L. Holle, and K. L. Cummins, 2002: The North American Lightning Detection Network (NALDN)—First Results: 1998-2000. Mon. Weather Rev., 130, 2098-2109, https://doi.org/10.1175/1520-0493(2002)130<2098:TNALDN>2.0.CO;2.

Penide, G., A. Protat, V. V. Kumar, and P. T. May, 2013: Comparison of Two Convective/Stratiform Precipitation Classification Techniques: Radar Reflectivity Texture versus Drop Size Distribution-Based Approach. J. Atmospheric Ocean. Technol., 30, 2788-2797, https://doi.org/10.1175/JTECH-D-13-00019.1.

Powell, S. W., Robert A. Houze, and S. R. Brodzik, 2016: Rainfall-Type Categorization of Radar Echoes Using Polar Coordinate Reflectivity Data. J. Atmospheric Ocean. Technol., 33, 523-538, https://doi.org/10.1175/JTECH-D-15-0135.1.

Roberto, N., and Coauthors, 2016: Multi-sensor analysis of convective activity in central Italy during the HyMeX SOP 1.1. Atmospheric Meas. Tech., 9, 535-552, https://doi.org/10.5194/amt-9-535-2016.

Romatschke, U., and R. A. Houze, 2011: Characteristics of precipitating convective systems in the South Asian monsoon. J. Hydrometeor.,.

- and _ 2013: Characteristics of Precipitating Convective Systems Accounting for the Summer Rainfall of Tropical and Subtropical South America. J. Hydrometeorol., 14, 25-46, https://doi.org/10.1175/JHM-D-12-060.1. 
— , and M. Dixon, 2022: Vertically Resolved Convective/Stratiform Echo Type Identification and Convectivity Retrieval for Vertically Pointing Radars. In preparation.,.

Saltikoff, E., and Coauthors, 2019: OPERA the Radar Project. Atmosphere, 10, 320 , https://doi.org/10.3390/atmos10060320.

Schumacher, C., and R. A. Houze, 2003: The TRMM Precipitation Radar's view of shallow, isolated rain. J. Appl. Meteorol., 42, 1519-1524.

Steiner, M., and R. A. Houze, 1997: Sensitivity of the Estimated Monthly Convective Rain Fraction to the Choice of Z-R Relation. J. Appl. Meteorol. Climatol., 36, 452-462, https://doi.org/10.1175/1520-0450(1997)036<0452:SOTEMC>2.0.CO;2.

,-- , and S. E. Yuter, 1995: Climatological characterization of three-dimensional storm structure from operational radar and rain gauge data. J. Appl. Meteorol. , 34, 1978-2007.

Thompson, E. J., S. A. Rutledge, B. Dolan, and M. Thurai, 2015: Drop Size Distributions and Radar Observations of Convective and Stratiform Rain over the Equatorial Indian and West Pacific Oceans. J. Atmospheric Sci., 72, 4091-4125, https://doi.org/10.1175/JAS-D-14-0206.1.

UCAR/NCAR-Earth Observing Laboratory, 2016: Radar regional mosaic, convective/stratiform classification in netCDF format. Version 1.0. UCAR/NCAR - Earth Observing Laboratory, https://doi.org/10.5065/D6M043SK.

Wang, Y., L. Tang, P.-L. Chang, and Y.-S. Tang, 2021: Separation of convective and stratiform precipitation using polarimetric radar data with a support vector machine method. Atmospheric Meas. Tech., 14, 185-197, https://doi.org/10.5194/amt-14-185-2021.

Yang, Y., X. Chen, and Y. Qi, 2013: Classification of convective/stratiform echoes in radar reflectivity observations using a fuzzy logic algorithm. J. Geophys. Res. Atmospheres, 118, 1896-1905, https://doi.org/10.1002/jgrd.50214.

Zhang, G., 2019: Weather Radar Polarimetry. CRC Press,.

Zhang, J., K. Howard, and J. J. Gourley, 2005: Constructing Three-Dimensional Multiple-Radar Reflectivity Mosaics: Examples of Convective Storms and Stratiform Rain Echoes. J. Atmospheric Ocean. Technol., 22, 30-42, https://doi.org/10.1175/JTECH-1689.1.

Zipser, E. J., D. J. Cecil, C. Liu, S. W. Nesbitt, and D. P. Yorty, 2006: Where are the most intense thunderstorms on earth? Bull. Am. Meteorol. Soc., 87, 1057-1071. 